University of Nebraska - Lincoln

DigitalCommons@University of Nebraska - Lincoln

Sociology Department, Faculty Publications

Sociology, Department of

2012

\title{
Adolescent Violent Victimization and Precocious Union Formation
}

Danielle C. Kuhl

Bowling Green State University, dckuhl@bgsu.edu

David F. Warner

University of Nebraska-Lincoln, dwarner3@unl.edu

Andrew Wilczak

Wilkes University, andrew.wilczak@wilkes.edu

Follow this and additional works at: https://digitalcommons.unl.edu/sociologyfacpub

Part of the Criminology Commons, and the Family, Life Course, and Society Commons

Kuhl, Danielle C.; Warner, David F.; and Wilczak, Andrew, "Adolescent Violent Victimization and Precocious Union Formation" (2012). Sociology Department, Faculty Publications. 195.

https://digitalcommons.unl.edu/sociologyfacpub/195

This Article is brought to you for free and open access by the Sociology, Department of at DigitalCommons@University of Nebraska - Lincoln. It has been accepted for inclusion in Sociology Department, Faculty Publications by an authorized administrator of DigitalCommons@University of Nebraska - Lincoln. 
Published in Criminology 50:4 (November 2012), pp. 1089-1127;

doi: 10.1111/j.1745-9125.2012.00288.x

Copyright (C) 2012 American Society of Criminology; published by Wiley-Blackwell.

Used by permission.

Published online September 12, 2012.

\title{
Adolescent Violent Victimization and Precocious Union Formation
}

\author{
Danielle C. Kuhl, Bowling Green State University \\ David F. Warner, The University of Nebraska-Lincoln \\ Andrew Wilczak, Wilkes University \\ Corresponding author - Danielle C. Kuhl, Department of Sociology, Bowling Green State University, \\ Williams Hall, Bowling Green, OH 43403; email dckuhl@bgsu.edu
}

Note: Supporting Information - including discussion of additional variables considered, Table S.1, and References - is presented at the end of this document.

This research was supported in part by the Center for Family and Demographic Research, Bowling Green State University, which has core funding from the Eunice Kennedy Shriver National Institute of Child Health and Human Development (Grant R24HD050959-07). D. F. Warner also received support from the National Center for Family \& Marriage Research, which is funded by a cooperative agreement (Grant 5 U01 AE000001-05) between the Assistant Secretary for Planning and Evaluation (ASPE) in the U.S. Department of Health and Human Services (HHS) and Bowling Green State University. The opinions and conclusions expressed herein are solely those of the author(s) and should not be construed as representing the opinions or policy of any agency of the federal government. An earlier version of this article was presented as part of the Speaker Series at Center for Families and Demographic Research, Bowling Green State University (January 18, 2012). We appreciate the comments of the anonymous reviewers and the Co-Editor, whose suggestions strengthened the article. We thank Al DeMaris and Wendy Manning for methodological advice early on, as well as Peggy Giordano, Kara Joyner, and Tara D. Warner for comments on previous drafts.

This research uses data from Add Health, a program project directed by Kathleen Mullan Harris and designed by J. Richard Udry, Peter S. Bearman, and Kathleen Mullan Harris at the University of North Carolina at Chapel Hill, and funded by grant P01-HD31921 from the Eunice Kennedy Shriver National Institute of Child Health and Human Development, with cooperative funding from 23 other federal agencies and foundations. No direct support was received from grant P01-HD31921 for this analysis. Special acknowledgment is due Ronald R. Rindfuss and Barbara Entwisle for assistance in the original design. Information on how to obtain the Add Health data files is available on the Add Health website - http://www.cpc.unc.edu/addhealth 


\begin{abstract}
This article bridges scholarship in criminology and family sociology by extending arguments about "precocious exits" from adolescence to consider early union formation as a salient outcome of violent victimization for youths. Research indicates that early union formation is associated with several negative outcomes; yet the absence of attention to union formation as a consequence of violent victimization is noteworthy. We address this gap by drawing on life course theory and data from the National Longitudinal Study of Adolescent Health (Add Health) to examine the effect of violent victimization ("street" violence) on the timing of first coresidential union formation-differentiating between marriage and cohabitation - in young adulthood. Estimates from Cox proportional hazard models show that adolescent victims of street violence experience higher rates of first union formation, especially marriage, early in the transition to adulthood; however, this effect declines with age, as such unions become more normative. Importantly, the effect of violent victimization on first union timing is robust to controls for nonviolent delinquency, substance abuse, and violent perpetration. We conclude by discussing directions for future research on the association between violent victimization and coresidential unions with an eye toward the implications of such early union formation for desistance.
\end{abstract}

Keywords: adolescence, violent victimization, life course, cohabitation, marriage

\begin{abstract}
A dolescents are at a substantial risk of experiencing violence, a large 1 portion of which occurs outside the home (Lauritsen, 2003). According to the National Survey of Children's Exposure to Violence (NatSCEV; Finkelhor, Turner, Ormrod, Hamby, et al., 2009), 60 percent of youth in the United States have been exposed to some form of violence in the past year37 percent had been assaulted without injury, 15 percent had been assaulted with a weapon and/or with injury, and 19 percent had witnessed community violence. The NatSCEV shows that violent victimization, especially assaults by peers and those involving injury, increases with age and peaks in late adolescence, such that more than 70 percent of youths 14 to 17 years of age report that they have been assaulted during their lifetimes. Indeed, adolescents 12 to 17 years of age are significantly more likely than adults to be victims of a nonfatal violent crime; they are twice as likely to be victims of robbery or aggravated assault and are almost three times as likely to be victims of simple assault, compared with those 18 years of age and older (Menard, 2002; Snyder and Sickmund, 2006).
\end{abstract}


Prior criminological research examining the consequences of adolescent victimization, particularly street and/or community violence, has focused largely on psychological and risk behavior outcomes for younger children and adolescents, such as depression, posttraumatic stress disorder, suicidal behaviors, substance use, aggression, and delinquency (Scarpa, 2001; Turner, Finkelhor, and Ormrod, 2006). Recent work also has linked adolescent violent victimization to early or "precocious exits" from adolescence-suicidal thoughts, high-school dropout, running away from home, teen pregnancy, and contact with the criminal justice system (Hagan and Foster, 2001; Haynie et al., 2009). Although this research has made strides toward understanding the developmental implications of street violence, Macmillan (2001: 14) argued for more research on adult transition markers such as the "formation of ties" and the "development of intimate relationships" to expand our understanding of how victimization shapes life course trajectories. However, scholars have not yet heeded this call. Life-course criminology has focused primarily on marriage as a key independent variable in desistance research (e.g., Sampson and Laub, 1990), which rests on the implicit assumption that marriage represents a prosocial role transition. Yet, prior research, particularly in family sociology, has shown that early coresidential union formation, especially marriage, is associated with a wide range of negative outcomes, as we review in the subsequent discussion (Amato and Booth, 1997; Uecker and Stokes, 2008; Wickrama, Wickrama, and Baltimore, 2010). ${ }^{1}$ Thus, the lack of attention to coresidential unions as the outcome of interest is a noteworthy gap in the precocious roles literature, especially considering the prevalence of violent victimization in adolescence and the fact that establishing intimate relationships is a key developmental task in adolescence and early adulthood (Collins, 2003).

To address this limitation, we use data from the National Longitudinal Study of Adolescent Health (Add Health) to examine the implications of adolescent violent victimization ("street" violence) for the timing of first coresi-

1. Accordingly, there are complexities in coresidential relationship formation - timing, for example - that may not position it as a universally beneficial transition. Criminology has only recently begun to recognize and explore some of these (Giordano, Schroeder, and Cernkovich, 2007). Indeed, as Uggen's (2000) work showed, some transitions do not have a universally positive influence on criminal behavior. Life-course criminology, however, is still in the early stages of challenging the "marriage is good" assumption and consequently has seldom examined unions as dependent variables (for exceptions, see King and South, 2011; Lonardo et al., 2010). 
dential unions - differentiating between cohabitation and marriage - in early adulthood. Although recent work has begun to examine the effect of violent offending on both cohabitation (Lonardo et al., 2010) and marriage (King and South, 2011), the consequences of adolescent violent victimization for either type of union formation remain unexplored. Add Health is well suited to this line of inquiry as it contains detailed information on the timing of respondents' coresidential relationships (both marriages and cohabitations), in addition to violent victimization experiences, from a contemporary cohort of young persons who have been followed well into their "marrying" years (up to 32 years of age). Grounded in life course theory (Elder, Johnson, and Crosnoe, 2003), our examination of the violent victimization-union timing association is consistent with the increasing recognition that early life experiences shape developmental processes and give rise to variability in the timing and sequencing of the transition to young adulthood (Settersten, 2003). With this premise in mind, we extend current research linking exposure to violence with premature exits from adolescence into adulthood (Hagan and Foster, 2001; Haynie et al., 2009). As we elaborate in this article, early union formation also may be a "precocious exit" - a risk behavior with negative long-term implications - that results from violent street victimization in adolescence. ${ }^{2}$

\section{Background}

\section{Violent Victimization in a Life Course Framework}

The life course is, to varying degrees, age graded, with social roles and activities allocated on the basis of age or life stage (Elder, Johnson, and Crosnoe, 2003; Settersten, 2003). This age structuring is formalized through institutionalized pathways - notably in the spheres of education and work-char-

2. Although youth experience several types of victimization-including family and intimate partner violence (IPV) - we focus exclusively on street violence given that this is the more prevalent form of victimization in adolescence. For instance, using the NatSCEV, Finkelhor, Turner, Ormrod, Hamby, et al. (2009; Finkelhor, Turner, Ormrod, and Hamby, 2009) found that among youth 14 to 17 years of age, 42.2 percent reported witnessing violence in the community, 26.5 percent reported being assaulted by a nonsibling peer, and 18.8 percent reported physical assault with injury in the past year, whereas 7.9 percent reported physical abuse by a parent and 5.6 percent reported dating violence in the past year. Previous studies reporting relatively high prevalence rates of IPV in adolescence (e.g., 38.2 percent in Miles and Malik, 1994, and 26.8 percent in Whitaker et al., 2007) focus only on those in romantic relationships and/or much older adolescents (see also Halpern et al., 2001) and thus do not provide a complete portrait of the victimization experiences of the general population of adolescents. 
acterized by sequentially arrayed roles and clear transitions from one role to the next. The sequential and interdependent nature of role transitions has led to much research devoted to understanding adolescence as a critical period in the life course. As Macmillan (2001: 6) discussed, adolescence is when the cognitive and psychological resources guiding decision making are developed (Clausen, 1991), and individuals acquire the human, social, and cultural capital that shape their later lives (Hagan, 1998). Thus, adolescence is when experiences and decisions are most apt to shape educational, occupational, and family trajectories going forward (Elder, Johnson, and Crosnoe, 2003; Johnson and Mollborn, 2009).

Given the developmental importance of these years, prior studies in criminology have identified violent victimization as a potentially disruptive force in adolescents' lives, highlighting its negative psychological and behavioral ramifications and finding, for example, that victims have a higher risk of suicidal thoughts and actions (Cleary, 2000), depressive symptoms (Latzman and Swisher, 2005), social anxiety (Siegel, La Greca, and Harrison, 2009), anger and aggression (Turner, Finkelhor, and Ormrod, 2006), and substance abuse (DeMaris and Kaukinen, 2005). Victims are also at an increased risk themselves of becoming offenders (Lauritsen, Sampson, and Laub, 1991; Menard, 2002) and of experiencing subsequent victimization (Finkelhor, Turner, Ormrod, Hamby, et al., 2009; Lauritsen and Quinet, 1995).

A limited number of studies indicate that adolescent victimization has important implications for personal and social development into adulthood. Adolescent violent victimization is an early life hardship that can disrupt the orderliness and timing of transitions to adulthood, propelling adolescents "toward experiences that challenge norms about childhood and adolescence" (Johnson and Mollborn, 2009: 43) as periods in the life course that are innocent and free from adult responsibilities, roles, and burdens. The violation of such age norms undermines one's sense of safety, control, and expectations for survival (Macmillan, 2001). These challenges to adolescents' self-concept may encourage them to assume adult roles and responsibilities at a point in the life course inconsistent with their normative timing.

Indeed, a prominent theme in recent research is that adolescent violent victimization may have a substantial effect on life trajectories by leading to the non-normative timing of events that mark the transition to adulthood. Both criminological theory and life course theory point to the importance of timing of events. In criminology, Thornberry's interactional theory gives credence to this developmental diversity, noting that as youth go through adolescence, "life circumstances change, developmental milestones are met (or, for some, missed), new social roles are created, and new networks of attachment and commitment emerge" (Thornberry, 1987: 881). In one of the first studies examining the influence of victimization on non-normative events, Hagan and 
Foster (2001) argued that adolescent victimization could severely disrupt the life course and prompt "precocious exits" from adolescence and premature entry into adulthood through various behavioral pathways, as a form of adaptation. They demonstrated that street violence (measured as witnessing and/or experiencing violence) is associated with increased depression, violent behavior, and teen pregnancy. A recent study by Haynie et al. (2009) found also that exposure to violent street victimization increased the risk of dropping out of high school. These outcomes mark a premature transition to adulthood; those who are not exposed to street violence remain in the adolescent phase of development. Their victimized peers, however, assume more "vulnerable" roles that can reduce their overall life chances. ${ }^{3}$ Rather than passive experiences, these role exits may be adolescent victims' attempt to assert agency over their lives by escaping "the confines of adolescence where they view themselves as having little control" (Haynie et al., 2009: 272). Thus, victims of violence may seek to "escape" adolescence by embarking on adult roles. One such adult role that is particularly salient in young adulthood is the formation of intimate coresidential unions. However, as with the other exits examined in prior studies, premature union formation is a role transition associated with reduced life chances.

\section{Adolescent Violent Victimization and Union Formation}

Family sociologists have long recognized that early intimate unions, especially marriage, have negative long-term consequences and thus may themselves be characterized as "risk behaviors" or "early exits" that could render one "off time" in the path to adulthood (Settersten, 2003). Consistent with life course theorizing on interconnected pathways, early marriage, more so than cohabitation, is associated with lower human capital accumulation for both partners (Thornton, Axinn, and Teachman, 1995). People who marry at younger ages report lower marital quality (Amato et al., 2007; Amato and Rogers, 1997) and are more likely to divorce than those who marry at older ages (Booth and Edwards, 1985; Teachman, 2002). Early cohabitating unions also are less stable-characterized by high rates of dissolution and unlikely to end in marriage (Schoen, Landale, and Daniels, 2007). Even for those early cohabitations that eventuate in marriage, instability is

3. Offending behavior and prior delinquency could themselves be "premature exits" from adolescence and are closely associated with violent victimization (Lauritsen and Quinet, 1995; Lauritsen, Sampson, and Laub, 1991). Accordingly, we account for both violent offending and nonviolent delinquency to guard against any spurious association between violent victimization and union timing in our subsequent analyses. 
increased as premarital cohabitation is associated with lower marital quality (Amato et al., 2007) and a higher risk of divorce (Teachman, 2002). Relationship instability, particularly divorce, is associated with lower economic, psychological, and physical well-being for both adults and children (Amato, 2000). Beyond the negative outcomes associated with the instability of these early unions, a recent study by Wickrama, Wickrama, and Baltimore (2010) found that early unions themselves are associated with several poor physical and mental health outcomes: Early marriage leads to obesity, whereas early cohabitation leads to increased likelihoods of smoking, being depressed, and having sexually transmitted diseases in young adulthood. Thus, precocious union formation often reduces life chances in various realms, which makes it a risky endeavor.

Despite this scholarship on the negative consequences of early unions, there remains a paucity of research on the risk factors for entering early unions, aside from demographic and family characteristics (Uecker and Stokes, 2008), and almost no research is available examining the influence of adolescent violent victimization on union formation in adulthood. Yet violent victimization can disrupt the normative age-graded transition from adolescence to adulthood, thereby producing these early exits. Specifically, violent victimization may lead to early union formation because it challenges adolescents' age identity, leading them to view their adult life course as less certain and to evaluate (subjectively) themselves as older (Johnson and Mollborn, 2009). Additionally, victims might seek out coresidential intimate relationships because of the need for intimacy and social support. Violent victimization leads to increases in loneliness and depression (Boivin, Hymel, and Hodges, 2001), is associated with feelings of social isolation and mistrust (Ross and Mirowsky, 2009), and compromises individuals' self-esteem (Guerra, Williams, and Sadek, 2011; Overbeek et al., 2010). Thus, victims may seek new attachments, prematurely shifting from peer attachments - reorganizing their "attachment hierarchy" (Kobak et al., 2007) - to form bonds with an intimate partner who can offer a renewed sense of efficacy. Forming a coresidential union could be a particularly attractive means of coping with the challenges to the self-concept brought on by violent victimization, particularly because victims who perceive high levels of emotional support report lower levels of depression and anxiety than victims who have low levels of emotional support (Ruback and Thompson, 2001). Victimization challenges the ability to view oneself in a positive light (Janoff-Bulman and Frieze, 1983); thus, victims may seek out intimate relationships to reaffirm their sense of self-worth. Coresidential partners, especially marital partners, are culturally expected to be one's greatest source of intimacy and social support (Waite and Gallagher, 2000). The formation of a coresidential union may be important for restoring trust in others, as violent victimization erodes one's sense of 
trust, undermining victims' belief in the world as meaningful, benign, trustworthy, and predictable (Ruback and Thompson, 2001). Finally, parents of youth who experience violence, or who live in violent neighborhoods, tend to be overprotective or controlling (Osofsky, 1995), which may prematurely spur adolescents into coresidential unions as a way of asserting independence from an authoritarian familial environment. Thus, for all of these reasons, the arguments put forth in the "early exits" studies (e.g., Hagan and Foster, 2001; Haynie et al., 2009) could apply equally to precocious union formation as another example of a "rush to adulthood" (Wickrama, Wickrama, and Baltimore, 2010).

The limited research on the association between early life victimization and union formation focuses primarily on family violence and/or female victims. For instance, Cherlin et al. (2004) found that among a sample of low-income women residing in urban areas, women with histories of childhood sexual abuse were more likely to have experienced short-term unions and these were primarily cohabiting unions. Neither childhood physical nor sexual abuse was associated with marital unions. However, it remains unknown whether other forms of victimization (e.g., "street violence") during a crucial phase of development (adolescence) have implications for marriage and cohabitation, or whether this victimization is relevant to the timing of those unions. Some research examining the influence of hardships (including violent victimization) on the timing of adult roles other than union formation is suggestive of such a linkage. For example, youth who experience victimization early in life feel older and take on parenting roles earlier (Hagan and Foster, 2001; Johnson and Mollborn, 2009). Likewise, a study by Brumbach, Figueredo, and Ellis (2009) found that youth who have witnessed or experienced community violence (or "harsh environments") displayed fewer long-term investments in adulthood (e.g., education, paid work, or income security) in part because they were more sexually permissive in adolescence, which the authors argued was evidence that "harshness" leads to greater effort in finding a mate rather than achieving "resource accruing potential" for an uncertain life course. Thus, whereas early first union formation may seem irrational because of its associated negative outcomes - those who jump into coresidential unions too soon would be mortgaging their futures - for youth exposed to street violence, such unions might actually represent a "faster life history strategy" (Brumbach, Figueredo, and Ellis, 2009) because of the tentativeness with which they view their life chances. As Booth, Rustenbach, and McHale (2008: 4) argued, youth from disadvantaged backgrounds may "make early family transitions because they expect to benefit from them."

Given the above arguments, adolescents who have experienced violent victimization not only may be more likely to form coresidential unions but also may do so at younger ages than their nonvictimized counterparts. It also is important to consider that cohabitation and marriage represent two distinct 
types of coresidential unions, and that cohabitation is increasingly viewed as an alternative to being single (Schoen, Landale, and Daniels, 2007). Because cohabitation and marriage are competing ways of forming a first residential union, this could mean that the effect of adolescent violent victimization on first union formation may depend on the type of union being considered. Cohabitation might be an attractive form of first union formation if victims are less trusting of others (Ruback and Thompson, 2001) and thus are less willing to commit to an intimate union through marriage. In contrast, violent victimization may have stronger effects on early marriage than cohabitation because marriage is a culturally privileged relationship status with expectations of intimacy, trust, and commitment (Waite and Gallagher, 2000). Of course, given a desire for intimacy and social support, violent victimization could be associated with increased rates of first union formation through both cohabitation and marriage.

\section{Current Study}

Drawing on life course theory and prior studies examining "early exits" in criminology, we examine whether adolescent violent victimization affects the timing of first union formation in young adulthood. We address two key questions:

1. How is adolescent violent victimization related to the timing of first union formation in young adulthood?

2. Does the effect of adolescent violent victimization on first union timing depend on the type of union - that is, does victimization differentially affect cohabiting versus marital first union formation?

We expect that violent victimization increases the rate of first union formation; yet it is possible that this effect declines with age in adulthood, as coresidential union formation becomes more normative and most young adults form such unions. When comparing marriage and cohabitation, the paucity of research examining the violent victimization-union formation link leaves us with no clear expectations as to whether the effect of victimization works similarly for each type of union.

\section{Data and Method}

Sample

We used data from the National Longitudinal Study of Adolescent Health (Add Health), which is an ongoing, nationally representative study of adolescent and now young adult health and well-being. A sample of 80 high schools 
and 52 feeder middle or junior high schools was selected through a disproportionately stratified, school-based, clustered sampling design; the sample was representative of U.S. schools with respect to region of country, urbanicity, school size, school type, and ethnicity (Harris et al., 2009). At wave I in 1994-1995, adolescents in grades 7 to 12 (11-21 years of age) in sampled schools were administered an In-School Questionnaire. A random subsample completed an In-Home Questionnaire in 1995 (N= 18,924 with valid sample weights). A subset of wave I respondents was reinterviewed in 1996 (wave II). The wave I sample was contacted for reinterview in 2001-2002 (wave III) when respondents were 18-26 years of age and in 2007-2008 (wave IV) when respondents were 24-32 years of age. Add Health offers several advantages for the current analysis including measurement of violent victimization and detailed information on the timing of marital and cohabiting relationships. Moreover, in contrast to other data sources often used to study the consequences of victimization such as the National Youth Survey (NYS), Add Health follows a contemporary cohort-an especially important fact given that most persons now form their first union via cohabitation (Kennedy and Bumpass, 2008).

We used information on violent victimization reported at wave I and assessed its effect on first coresidential union timing using detailed relationship histories reported at waves III and IV. Given the focus on first union timing, we restricted our analytic sample in several ways. First, we limited our analyses to respondents with valid information on the year and month of their first coresidential union and with a valid birth year and month. This excluded 245 cases - 231 of which were missing first union dates. Second, we limited our analysis to respondents ever observed after their 17 th birthday. ${ }^{4}$ Union formation is a developmental process, and coresidential relationships, especially marriages, formed prior to this age are highly selective (Amato and Booth, 1997; Wolfinger, 2003). This excluded a total of 975 respondents, including 289 respondents who were never observed after reaching 17 years of age and 686 who were observed but reported forming a coresidential union prior to 17 years of age. Finally, we limited our analysis to respondents with complete information on all study covariates. Missing information was minimal, with most indicators missing for less than 1 percent of the sample. The ex-

4. Given the age heterogeneity of the Add Health sample, prior studies have dealt with the developmental nature of relationship formation by limiting their analyses to respondents of a certain age or grade level at the initial observation (e.g., Raley, Crissey, and Muller, 2007). Such a restriction eliminates nearly 63 percent of the sample. By contrast, our approach allows respondents to "age into" the risk set after achieving their 17th birthday and results in a loss of only slightly more than 5 percent of the available cases. We also conducted supplemental analyses using 16 and 18 years of age as alternative sample selection ages, and the results were substantively similar to those presented. 
ception to this was family socioeconomic status (SES) at wave I, where approximately 5.4 percent of the sample was missing. Overall, we excluded 1,631 respondents (9.2 percent of the remaining sample) because of missing data. ${ }^{5}$ Our final analytic sample contained 16,077 respondents, approximately half of whom were women (49.5 percent). Racial/ethnic minority respondents comprised approximately one third of our sample, with 14.9 percent of respondents identifying as Black and 11.1 percent identifying as Hispanic. More than two thirds (69.5 percent) of respondents were observed to form a first coresidential union between 17 and 32 years of age, with most respondents forming cohabiting first unions (56.0 percent) as opposed to marital first unions (13.5 percent) as expected (Bumpass and Lu, 2000).

\section{Measures}

\section{Dependent Variables}

Our dependent variables were the rate at which respondents formed their first coresidential marital or cohabiting partnership. ${ }^{6}$ We identified the timing of respondents' first unions based on detailed histories on all coresidential partnerships collected at waves III and IV. Respondents indicated the month and year each partnership began and ended, and whether it was a marriage or cohabiting relationship. We arrayed the relationships in chronological order to identify respondents' age at their first coresidential union and created separate measures distinguishing between cohabitation or marriage (without prior cohabitation). We coded respondents who formed their first cohabitation and marriage in the same month as first entering a marital union on the assumption that the premarital cohabitation was with the clear intention to marry (Stanley, Rhoades, and Markman, 2006).

\section{Focal Independent Variable}

Violent victimization was assessed by wave I reports of how often in the past 12 months 1) "someone had pulled a knife or gun" on them, 2) "someone cut or stabbed" them, 3) "someone shot" them, or 4) they "were

5. In preliminary analyses, we used multiple imputation to assess the extent to which these missing data exclusions affected our results. These results were largely similar to those obtained with listwise deletion, suggesting that any bias resulting from these missing data exclusions was negligible.

6. While prior studies (e.g., Ryan et al., 2009; Wickrama, Wickrama, and Baltimore, 2010) have defined early union formation as that occurring before some chronological age, often in reference to the population averages, such designations are arbitrary, especially because statistical and social age norms are not synonymous (Settersten, 2003). 
jumped." Responses for all items were "never," "once," and "more than once." Given the low prevalence of each item, we created a dummy indicator for any experience of violent victimization $(=1$; no experience $=0)$. In preliminary analyses, we did not detect any statistically significant differences in the rate of union formation between respondents who experienced only one act and those who experienced two or more acts of victimization. Although our measure of violent victimization references incidents only in the past 12 months, we recognize that current victims are likely to have been past (and to be future) victims (Finkelhor, Turner, Ormrod, Hamby, et al., 2009; Lauritsen and Quinet, 1995).

Although we cannot be certain of the context in which adolescents experienced victimization (e.g., the victim-offender relationship), two things suggest that our measure of violent victimization reflects "street" violence in the broadest sense. First, the results we present were robust to controls for having been either physically or sexually abused by a parent, which Cherlin et al. (2004) showed to be associated with union formation. We direct readers to the online supporting information for more detail on these supplemental analyses. ${ }^{7}$ This indicates that our measure of adolescent violent victimization is not capturing familial violence. Second, the incidence of violent victimization in the past year was greater for male (28.3 percent) than for female adolescents (11.5 percent), as would be expected if the measure were capturing street violence as opposed to interpersonal violence. ${ }^{8}$ Moreover, the effect of violent victimization on the risk of union formation was not statistically different by gender (see footnote 10), which suggests that our measure of victimization operates similarly for men and women (an unlikely occurrence if the measure were tapping different types of violence).

7. Additional supporting information can be found at the end of this document.

8. Data limitations prevented us from testing this assertion directly. IPV was first asked of Add Health respondents at wave II-but not all respondents were eligible for wave II interviews. As a result, limiting our analyses to persons with valid wave I and wave II data would result in at least a 27 percent case loss $(n=$ $4,337)$. The fact that IPV is measured more proximate to union formation is also likely problematic because, as Hagan and Foster (2001: 880-1) noted, this advantages IPV in the causal chain. Furthermore, it would be important to distinguish between perpetration and victimization, given differences in these roles within intimate dyads; unfortunately, perpetration was not asked about until wave III. Past studies (e.g., Haynie et al., 2009) have collapsed IPV and street violence into a single measure, but this does not allow researchers to assess the impact of either type of victimization. 


\section{Control Variables}

To guard against any spurious associations, we controlled for several factors that prior work has suggested may be correlated with both adolescent violent victimization and the rate of union formation. These measures are divided among demographic characteristics, the family of origin environment, deviant behavior, and emotional and social dispositional characteristics. All controls were measured at wave I.

Demographic characteristics included age, race/ethnicity, immigrant status, family socioeconomic status, residence in an urban area, and region. Age at the first interview is measured with a continuous variable ranging from 11.42 to 21.33 years. Including this measure accounts for the fact that our initial sample is age heterogeneous, and reports from younger respondents are more removed from the timing of their coresidential unions. Race/ethnicity was captured with a series of mutually exclusive dummy variables for Black, Hispanic, Asian, and Native American/other, with White serving at the reference group. Immigrant was a dummy variable coded 1 if the respondent was not born in the United States. We constructed Family SES based on respondents' reports of their resident parents' educational attainment and usual occupation (Bearman and Moody, 2004). The resulting ordinal indicator ranges from 0 to 9 , with higher values indicating higher family SES. We used information from the wave I contextual file to construct a dummy variable for Urban residence, where 1 indicates that the respondent lived in an entirely urbanized area. Finally, we used a set of mutually exclusive dummy variables for Northeast, Midwest, and West, with South serving as the reference, to account for known regional differences in normative union formation ages (Uecker and Stokes, 2008) and potential regional differences in violent victimization.

We included three measures of respondents' family of origin environment implicated in both the potential for adolescent violent victimization and subsequent union formation behavior. Live with biological parents is a dummy variable coded 1 if respondents reported living with both their biological mother and biological father. Youth who live in single-parent families have higher risks of victimization (Lauritsen and Quinet, 1995) and higher risks of cohabitation and early marriage (Amato and Booth, 1997; Ryan et al., 2009; Wolfinger, 2003) than youth from two-parent families. Such family structure effects may be due, in part, to lower levels of supervision (Esbensen, Huizinga, and Menard, 1999) in single-parent families and stepfamilies; we thus included two measures to account for this possibility. Autonomy is a count of seven activities about which respondents indicated that their "parents let [them] make their own decisions," including choice in friends, clothing, and meals; amount and type of television viewing; weeknight bedtime; and weekend curfew (Felson and Haynie, 2002). As most ad- 
olescents reported at least 1 or 2 activities over which they had autonomy, we recoded this measure such that $0=2$ or fewer activities to $5=$ all activities. Respondents also were asked about the frequency with which they lied to their parents or guardians "about where [they] had been or whom [they] were with" in the past year with responses ranging from "never" to "five or more times." Given that fewer than half of adolescents reported never having lied to their parents, we coded Lie to parents as a dummy variable where 1 indicates having lied three or more times.

Given the well-established link between victimization and offending (see footnote 3), we controlled for several measures of respondents' deviant behavior, including violent perpetration, nonviolent delinquency, and substance use. Although studies linking violent and delinquent behavior to union formation in young adulthood are rare, a recent study by King and South (2011) suggested that serious criminal behavior is associated negatively with marital timing for men - although this effect is largely due to the lower desire of offenders to be married. Violent perpetration is based on respondents' reports of how often in the past 12 months they had 1) been in "a serious physical fight," 2) "hurt someone badly enough to need bandages or care from a doctor or nurse," 3) used or threatened to use "a weapon to get something from someone," or 4) participated "in a fight where a group of [their] friends was against another group." Responses for all items were "never," "1 or 2 times," "3 or 4 times," and "5 or more times." Because of the low prevalence of each measure, we dichotomized them and created a count ranging from none $(=0)$ to four $(=4)$. Preliminary analyses indicated that this specification provided a better model fit than either a dummy variable or nonlinear alternatives.

We measured Nonviolent delinquency with a mean rating scale of the frequency with which respondents committed ten delinquent or undesirable behaviors in the past 12 months. These behaviors included things such as "paint[ing] graffiti," "driving a car without its owner's permission," and "stealing something valued at more than $\$ 50$ " $(\alpha=.80)$ Responses ranged from "never" $(=0)$ to "5 or more times" $(=3)$ in the past 12 months. We included two measures of substance use. Alcohol use was specified as an ordinal indicator of the number of days in the past 12 months that the respondent drank, ranging from "never drank/zero days" (=1) to "every day" (=6). Illicit Drug use was measured with a dummy variable for any use of marijuana, cocaine, or any "other type of illegal drug" within the past 30 days. We created a single dichotomous measure because of the low prevalence of drug use aside from marijuana.

Finally, we included indicators for dispositional characteristics that may link violent victimization to the timing of union formation, with several measures related to psychological traits, physical development, and expec- 
tations about union formation. Prior studies (Hagan and Foster, 2001; Sampson and Laub, 1993) have found certain psychological traits - including depression and self-efficacy - related to both exposure to violence and various "early exits" from adolescence (although these studies have not examined union formation). Consequently, we controlled for depression with a summated scale of 19 Depressive symptoms adapted from the CES-D; examples of these items include questions about the frequency during the past week that respondents felt sad, they could not shake the blues, too tired to do things, and that people disliked them, with responses ranging from "never" $(=0)$ to "most" or "all of the time" $(=3)(\alpha=.87)$. We controlled for selfefficacy with a four-item mean rating scale of Instrumental problem solving. Respondents were asked the extent to which they agreed with statements such as, "When you have a problem to solve, one of the first things you do is get as many facts about the problem as possible" and "After carrying out a solution to a problem, you usually try to analyze what went right and what went wrong." Responses were coded from strongly disagree $(=0)$ to strongly agree $(=4)$. Higher scores signify greater instrumental problem solving $(\alpha=.74)$.

We controlled for Relative pubertal development to account for differences in physical maturity that may be associated with victimization and movement into adult intimate relationships. Prior studies have indicated that early pubertal development is associated with violence and delinquency among both adolescent boys and girls (Felson and Haynie, 2002; Haynie and Piquero, 2006). Also, pubertal development is positively associated with early sexual debut (Halpern et al., 2006) and, at least among earlier cohorts, union formation (Kiernan, 1977). Given that designations of early or late pubertal development are age graded, we employed a measure of development relative to one's same-age peers (see Halpern et al., 2006). Respondents were asked to rate their "physical development compared to other boys [girls]" their age, with responses that they looked "younger than most," "younger than some," "about average," "older than some," and "older than most." We coded this measure to range from -2 to 2 , with 0 equal to "about average."

Young adults who place greater importance on religion are more likely to marry and less likely to cohabit than others (Thornton, Axinn, and Hill, 1992). Likewise, pro-marriage expectations predict union formation (Clarkberg, Stolzenberg, and Waite, 1995). Religion is also a buffer against violent victimization, perhaps due to the way that it structures daily activities or inhibits associations with deviant peers (Schreck, Burek, and Clark-Miller, 2007). Consequently, we controlled for Religious importance with an ordinal measure ranging from "not at all important" $(=0)$ to "very important" $(=3)$. We controlled for the expectation to Marry by age 25 with an ordinal measure based on respondents" reports of "the chance [they] will be married by 
age 25 " with responses ranging from "almost no chance" (=0) to "almost certain" $\left.^{\prime \prime}=4\right){ }^{9}$

\section{Analytic Approach}

We used Cox proportional hazard models to assess the effect of adolescent violent victimization on the rate of entry into first unions. Cox models are advantageous because they allow estimation of the covariate effects on the risk of union formation without requiring specification of the baseline hazard rate (Allison, 1984). Accordingly, they have been used in several studies of union formation (e.g., Raley, Crissey, and Muller, 2007; Teachman, 2003).

As young adults may enter their first coresidential union through either cohabitation or marriage, we estimated a competing risks model of first union formation. Under competing risks, the formation of one type of coresidential union (e.g., cohabitation) removes an individual from the risk of the other type of coresidential union (e.g., marriage). Our basic competing risks model predicting the rate of union formation is as follows:

$$
\log h_{i j}(t)=\lambda_{0 i j}(t)+\beta_{1} \operatorname{Victim}_{1 i j}+\boldsymbol{\beta}_{2} \text { Controls }_{2 i j^{\prime}} \quad \text { for } j=1,2
$$

Here, the age-specific risk of a first union formation for individual $i$, given that the transition is of union type $j$ (e.g., marriage) and that the individual has survived to at least age $t$ without experiencing another, competing transition (e.g., cohabitation), is a function of an unspecified baseline hazard rate $\left(\lambda_{0 i j}(t)\right)$, the effect of adolescent violent victimization $\left(\beta_{1}\right)$, and a vector of control variables $\left(\boldsymbol{\beta}_{2}\right)$ for demographic characteristics, family environment, deviant behavior, and disposition as described earlier. We tested the equality of coefficients (Paternoster et al., 1998) to determine whether the effect of a given parameter differed between the models for first marital and first cohabiting unions.

Although known as a proportional hazards model, the Cox model is easily extended to include nonproportionality, allowing examination of whether the effect of a given variable on the rate of union formation changes with age. As discussed, we suspected that the effect of adolescent violent victimization would decline with age as the incidence of first union formation increased in the population - that is, as the formation of coresidential unions became more

9. We controlled for several additional measures in preliminary analyses (see the online supporting information for further details), such as dropping out of high school, parent-adolescent relationship characteristics, problem drinking, intelligence, having a temper, and expectations of going to college. We excluded them from final models because they were not associated with union formation or did not change the effect of street victimization once included. 
developmentally normative. Our preliminary analyses bore out this suspicion, and thus, we incorporated this nonproportional effect in our final models as follows:

$\log h_{i j}(t)=\lambda_{0 i j}(t)+\beta_{1} \operatorname{Victim}_{1 i j}+\beta_{2}$ Controls $_{2 i j}+\beta_{3}$ Controls $_{3 i j^{\prime}}$ for $j=1,2(2)$

Equation 2 is identical to Equation 1, save for the addition of the interaction between adolescent violent victimization and age $\left(\beta_{2}\right)$, which allows for the diminishing effect of violent victimization on the rate of union formation with age. ${ }^{10}$

We specified that the age-specific risk of union formation began on a respondent's 17th birthday, modeling this risk in terms of the number of months beyond this date. Because we control for age at the first interview, to avoid confusion, we refer to the number of months beyond 17 years of age as "time." Some Add Health respondents were older than 17 years of age at the first interview, and thus, their exposure intervals were left truncated. For these respondents, the risk interval began at the date of their first interview. Under our competing risks analysis, respondents remained at risk of experiencing the focal transition (e.g., cohabitation) until they experienced that transition, experienced the nonfocal transition (e.g., marriage), or were right-censored at their final interview because they were continuously unpartnered (Allison, 1984).

\section{Results}

Table 1 contains sample descriptive statistics for the total sample and by adolescent violent victimization status. Approximately one fifth (19.2 percent) of respondents reported being violently victimized in the year prior to their first interview. Compared with nonvictims, victims were slightly older, more likely to be male, Black or Hispanic, from lower SES families, and more likely to re-

10. Preliminary analyses also identified nonproportional differences in the rate of first union formation by gender. This was expected because women initially have a higher rate of union formation (i.e., women enter unions at younger ages), but this difference declines with age as men's rate of first union formation accelerates. However, our preliminary analyses indicated that the time-varying effect of adolescent violent victimization did not differ significantly by gender (see also Hagan and Foster, 2001), and there were few statistically significant gender differences in the effects of our control variables on the rate of union formation. Thus, we present pooled analyses and constrain the effect of being female to be proportional with age. Ignoring this nonproportional effect is of no statistical consequence in our Cox models, and the time-invariant effect of being female represents the average effect over the range of observed times (Allison, 1984). 
Table 1. Sample Descriptive Statistics, by Adolescent Violent Victimization: Means (Standard Errors) and $t$ Tests ${ }^{\mathrm{a}, \mathrm{b}}$

\begin{tabular}{|c|c|c|c|c|c|c|}
\hline \multirow[t]{2}{*}{ Variables } & \multirow[b]{2}{*}{ Mean } & \multirow[b]{2}{*}{ (SE) } & \multicolumn{2}{|c|}{ Nonvictims } & \multicolumn{2}{|l|}{ Victims } \\
\hline & & & Mean & (SE) & Mean & (SE) \\
\hline \multicolumn{7}{|l|}{ Focal Variable } \\
\hline Violent victimization & .192 & - & - & - & - & - \\
\hline \multicolumn{7}{|l|}{ Demographic Characteristics } \\
\hline Age at first interview & 15.963 & $(.112)$ & $15.915^{\mathrm{c}}$ & $(.115)$ & 16.165 & $(.124)$ \\
\hline Female & .495 & & $.546^{\mathrm{c}}$ & & .282 & \\
\hline \multicolumn{7}{|l|}{ Race/ethnicity } \\
\hline White & 687 & - & $.709^{c}$ & - & .593 & - \\
\hline Black & 149 & - & $.135^{\mathrm{c}}$ & - & .210 & - \\
\hline Hispanic & .111 & - & $.102^{\mathrm{c}}$ & - & .149 & - \\
\hline Asian & .036 & - & .037 & - & .029 & - \\
\hline Native American/other & .016 & - & .016 & - & .019 & - \\
\hline Immigrant & .061 & - & .062 & - & .057 & - \\
\hline Family SES & 4.571 & $(.110)$ & $4.674^{\mathrm{c}}$ & $(.115)$ & 4.137 & $(.111)$ \\
\hline Urban & .514 & - & $.495^{c}$ & - & .594 & - \\
\hline \multicolumn{7}{|l|}{ Region } \\
\hline Northeast & .138 & - & .140 & - & .130 & - \\
\hline Midwest & .320 & - & .324 & - & .303 & - \\
\hline South & .381 & - & .381 & - & .378 & - \\
\hline West & .161 & - & .155 & - & .188 & - \\
\hline \multicolumn{7}{|l|}{ Family Environment } \\
\hline Live with biological parents & .582 & - & $.612^{\mathrm{c}}$ & - & .459 & - \\
\hline Autonomy & 3.189 & $(.049)$ & 3.175 & $(.049)$ & 3.250 & $(.065)$ \\
\hline Lie to parents & .231 & - & $.202^{\mathrm{c}}$ & - & .350 & - \\
\hline \multicolumn{7}{|l|}{ Deviant Behavior } \\
\hline Violent perpetration & .714 & $(.020)$ & $.480^{\circ}$ & $(.013)$ & 1.699 & $(.037)$ \\
\hline Nonviolent delinquency & .286 & $(.006)$ & $.231^{\mathrm{c}}$ & $(.007)$ & .517 & $(.014)$ \\
\hline Alcohol use & 1.111 & $(.041)$ & $.972^{\mathrm{c}}$ & $(.042)$ & 1.694 & $(.063)$ \\
\hline Drug use & .158 & - & $.124^{\mathrm{c}}$ & - & .299 & - \\
\hline \multicolumn{7}{|l|}{ Disposition } \\
\hline Depressive symptoms & 10.661 & $(.134)$ & $10.095^{c}$ & $(.132)$ & 13.046 & $(.216)$ \\
\hline Instrumental problem solving & 2.791 & $(.010)$ & $2.799^{c}$ & $(.010)$ & 2.759 & $(.017)$ \\
\hline Relative pubertal development & .249 & $(.015)$ & $.225^{c}$ & $(.015)$ & .347 & $(.038)$ \\
\hline Religious importance & 2.019 & $(.029)$ & $2.052^{\mathrm{c}}$ & $(.031)$ & 1.882 & $(.036)$ \\
\hline Expect to marry by age 25 & 2.234 & $(.022)$ & $2.260^{c}$ & $(.023)$ & 2.127 & $(.030)$ \\
\hline$N$ of respondents ${ }^{\mathrm{d}}$ & 16,077 & & 12,907 & & 3,170 & \\
\hline
\end{tabular}

Abbreviations: $\mathrm{SE}$ = standard error (omitted for dummy variables); $\mathrm{SES}=$ socioeconomic status.

a. Means for dummy variables can be interpreted as the proportion of the sample coded 1 on that indicator.

b. All analyses are weighted and corrected for survey design.

c. Statistically significant difference $(p<.05)$ between nonvictims and victims.

d. Unweighted $N$.

Source: National Longitudinal Study of Adolescent Health (Add Health), 1995-2008.

side in urban areas. Victims and nonvictims report different family environments as well, with victims less likely to be living with both biological parents and more likely to have lied to their parents about their whereabouts at least 
Table 2. Descriptive Statistics for Union Timing, by Adolescent Violent Victimization: Means (Standard Errors) and $t$ Tests ${ }^{\mathrm{a}, \mathrm{b}}$

\begin{tabular}{|c|c|c|c|c|c|c|}
\hline \multirow[t]{2}{*}{ Variables } & \multirow[b]{2}{*}{ Mean } & \multirow[b]{2}{*}{ (SE) } & \multicolumn{2}{|c|}{ Nonvictims } & \multicolumn{2}{|c|}{$\underline{\text { Victims }}$} \\
\hline & & & Mean & (SE) & Mean & (SE) \\
\hline \multicolumn{7}{|l|}{ First Union Status } \\
\hline Any union & .695 & - & .695 & - & .695 & - \\
\hline Cohabitation & .560 & - & .555 & - & .580 & - \\
\hline Marriage & .135 & - & $.140^{c}$ & - & .115 & - \\
\hline \multicolumn{7}{|l|}{ Age at First Union ${ }^{\mathrm{d}}$} \\
\hline Any union & 21.790 & $(.084)$ & $21.905^{c}$ & $(.088)$ & 21.308 & $(.099)$ \\
\hline Cohabitation & 21.723 & $(.082)$ & $21.832^{\mathrm{c}}$ & $(.087)$ & 21.283 & $(.095)$ \\
\hline Marriage & 23.582 & $(.103)$ & $23.656^{c}$ & $(.104)$ & 23.223 & $(.159)$ \\
\hline$N$ of respondents $\mathrm{e}$ & 16,077 & & 12,907 & & 3,170 & \\
\hline
\end{tabular}

Abbreviation: $\mathrm{SE}=$ standard error (omitted for dummy variables).

a. Means for dummy variables can be interpreted as the proportion of the sample coded 1 on that indicator.

b. All analyses are weighted and corrected for survey design.

c. Statistically significant difference $(p<.05)$ between nonvictims and victims.

d. Sample size is limited to those observed to form a given union and accordingly varies across union type.

e. Unweighted $N$.

Source: National Longitudinal Study of Adolescent Health (Add Health), 1995-2008.

three times. Consistent with prior studies, violent victimization and perpetration were associated, with victims reporting having engaged in 3.5 times the number of violent acts in the past year that nonvictims did. Victims also reported that they committed more nonviolent delinquent acts, drank alcohol more frequently, and were more likely to have used illicit drugs. Victims reported more depressive symptoms, exhibited slightly lower instrumental problem solving, and judged their pubertal development to be slightly ahead of their peers. Finally, victims expressed lower levels of religious importance and appraised their chances of being married by 25 years of age as slightly lower.

The first union formation behavior of respondents is summarized in Table 2, where we present two measures - the percentage of respondents who ever formed first unions during the observation period and the average age at which they formed those unions. Nearly 70 percent of young adults have formed their first coresidential union by their early 30s (at approximately 21 years and 9 months of age), with 56 percent forming a cohabiting and 13.5 percent forming a marital first union (Bumpass and $\mathrm{Lu}, 2000$ ). As expected, those forming cohabiting first unions were significantly younger than those who formed marital first unions (21.7 vs. 23.6 years of age, respectively).

Given the significant differences between victims and nonvictims in the known correlates of union formation described, we would expect to observe differences in first union timing as well. Indeed, as the means for age at first 
union demonstrate, we do observe evidence that adolescent violent victimization is associated with earlier union formation. Among those respondents who formed first unions, victims were about half a year younger than nonvictims when they entered the union - whether this was a cohabiting or marital first union. These differences in timing are key, given that nearly identical percentages of victims and nonvictims formed any type of coresidential first union during the observation period (and, in fact, fewer victims had formed marital first unions than nonvictims by their early 30s).

Comparing these two relatively crude indicators, we have an emerging picture about the effect of adolescent violent victimization on union formation in young adulthood. Street victimization seems to be associated with early cohabiting and marital union formation, given the younger age at which victims form unions. However, this effect seems to wane with age, as the overall prevalence of first union formation does not significantly differ by the time victims and nonvictims enter their early 30s. We now turn to the Cox proportional hazard model results to examine whether violent victimization indeed affects the timing of union formation.

\section{Multivariate Results}

\section{First Union Formation}

We first examined the effect of adolescent violent victimization on the risk of any first union formation. We present two models in Table 3. Model 1 shows the baseline effect of violent victimization on the rate of union formation, including the interaction with time identified in our preliminary analyses (described previously; see equation 2). Model 2 shows the effect of violent victimization after adjustment for the full set of controls. As hazard coefficients $(b)$ lack intuitive meaning, we also present hazard ratios $\left(\mathrm{HR}=\mathrm{e}^{b}\right)$. Supplemental analyses entering our control variables in a stepwise fashion yielded a pattern of effects largely similar to those presented in the full model; we note where any differences occurred in our subsequent discussion.

As suggested by our descriptive statistics, we find clear evidence that adolescent violent victimization increases the rate of union formation, with victims forming unions more quickly and thus at younger ages than nonvictims. However, the significant negative interaction with time indicates that the effect of victimization decreases with age (model 1). Adolescents experiencing violent victimization in the year prior to their first interview have 1.489 times the risk of forming any type of first coresidential union at 17 years of age compared with nonvictims. Each month after 17 years of age, the risk of any first union formation declines by a multiplicative factor of .996. Stated differently, the rate of first union formation for victims is 49 percent higher than the rate for nonvictims at 17 years of age, with the disparity declining by about .4 
Table 3. Adolescent Violent Victimization and the Risk of Any First Union Formation, Cox Proportional Hazard Model Estimates $(N=16,077)^{\mathrm{a}, \mathrm{b}}$

\begin{tabular}{|c|c|c|c|c|c|c|}
\hline \multirow[t]{2}{*}{ Variables } & \multicolumn{3}{|l|}{ Model 1} & \multicolumn{3}{|l|}{ Model 2} \\
\hline & $b$ & $(\mathrm{SE})$ & HR & $b$ & (SE) & HR \\
\hline \multicolumn{7}{|l|}{ Focal Variable } \\
\hline Violent victimization & $.398^{* * *}$ & $(.058)$ & 1.489 & $.399^{* * *}$ & $(.056)$ & 1.491 \\
\hline Violent victimization $\times$ Time $^{c}$ & $-.004^{\star * *}$ & $(.001)$ & .996 & $-.004^{* * *}$ & $(.001)$ & .996 \\
\hline \multicolumn{7}{|l|}{ Demographic Characteristics } \\
\hline Age at first interview & & & & $-.026^{*}$ & (.012) & .974 \\
\hline Female & & & & $.388^{* * *}$ & $(.031)$ & 1.474 \\
\hline \multicolumn{7}{|l|}{ Race/ethnicity } \\
\hline White & & & & - & & \\
\hline Black & & & & $-.362^{* * *}$ & $(.050)$ & .696 \\
\hline Hispanic & & & & $-.171^{* *}$ & $(.056)$ & .843 \\
\hline Asian & & & & $-.327^{* *}$ & (.111) & .721 \\
\hline Native American/other & & & & $-.299^{\dagger}$ & (.151) & .742 \\
\hline Immigrant & & & & -.056 & $(.072)$ & .946 \\
\hline Family SES & & & & $-.053^{* * *}$ & $(.005)$ & .949 \\
\hline Urban & & & & $-.137^{* *}$ & $(.045)$ & .872 \\
\hline \multicolumn{7}{|l|}{ Region } \\
\hline Northeast & & & & $-.307^{* * *}$ & $(.053)$ & .746 \\
\hline Midwest & & & & -.028 & $(.056)$ & .972 \\
\hline South & & & & - & & \\
\hline West & & & & -.066 & $(.066)$ & .936 \\
\hline \multicolumn{7}{|l|}{ Family Environment } \\
\hline Live with biological parents & & & & $-.147^{* * *}$ & $(.030)$ & .863 \\
\hline Autonomy & & & & .009 & (.010) & 1.009 \\
\hline Lie to parents & & & & $.081^{*}$ & $(.037)$ & 1.084 \\
\hline \multicolumn{7}{|l|}{ Deviant Behavior } \\
\hline Violent perpetration & & & & $.061^{* * *}$ & (.018) & 1.063 \\
\hline Nonviolent delinquency & & & & -.044 & $(.057)$ & .957 \\
\hline Alcohol use & & & & $.025^{*}$ & $(.010)$ & 1.025 \\
\hline Drug use & & & & .055 & $(.045)$ & 1.056 \\
\hline \multicolumn{7}{|l|}{ Disposition } \\
\hline Depressive symptoms & & & & .004 & $(.003)$ & 1.004 \\
\hline Instrumental problem solving & & & & .028 & $(.027)$ & 1.028 \\
\hline Relative pubertal development & & & & $.029^{*}$ & $(.011)$ & 1.029 \\
\hline Religious importance & & & & -.024 & $(.015)$ & .976 \\
\hline Expect to marry by age 25 & & & & $.071^{* * *}$ & $(.014)$ & 1.074 \\
\hline$N$ of events & & & & 11,040 & & \\
\hline
\end{tabular}

Abbreviations: $\mathrm{HR}=$ hazard ratio; $\mathrm{SE}$ = standard error (omitted for dummy variables); $\mathrm{SES}$ = socioeconomic status.

a. $\mathrm{HR}=\exp (b)$.

b. All analyses are weighted and corrected for survey design.

c. Time is measured in person months after 17 years of age.

$\dagger p<.10 ; * p<.05 ;{ }^{* *} p<.01 ; * * * p<.001$ (two-tailed tests)

Source: National Longitudinal Study of Adolescent Health (Add Health), 1995-2008.

percent each month thereafter. The effect of victimization declines with age such that by 24 years and 6 months of age, victims and nonvictims are about equally likely to form a first union, provided they had not yet formed one. At 
older ages, victims are actually less likely than nonvictims to do so (calculations not shown).

Adjusting for demographic characteristics, family environment, deviant behavior, and disposition did not alter the effect of violent victimization on the rate of first union formation (model 2). Net of the control variables, adolescent violent victimization continues to increase the rate of union formation at 17 years of age by approximately 49 percent and this difference declines by .4 percent with each additional month. Although not displayed in the table, we note that adjusting for female actually increased the effect of violent victimization substantially $(\mathrm{HR}=1.704)$, indicating that female operated as a suppressor, given that women form first unions at earlier ages but were less likely to report violent victimization than men. The increased effect of violent victimization was reduced by the combination of the remaining variables, although living with biological parents and violent perpetration were responsible for most of the reduction. As Table 3 also shows, the effects of our control variables on the rate of union formation largely conform to prior research.

\section{Type of First Union Formation: Cohabitation or Marriage}

The results presented thus far indicate that adolescent violent victimization increases the rate of union formation, but it is not clear whether this effect differs between cohabiting and marital first unions. To answer this question, we turn to the competing risks Cox model specified previously. As with the analyses of any first union formation, we present both unadjusted (model 1 ) and fully adjusted (model 2) estimates for each type of union transition in Table 4 .

Overall, our competing risks analysis indicates that adolescent violent victimization increases the rate of first union formation via both cohabitation and marriage-however, the effect on marriage is both more pronounced and wanes more quickly with age. Examining the unadjusted model for cohabitation first, we find that violent victimization increases the rate at which young adults form cohabiting first unions by approximately 46 percent at 17 years of age, with the disparity in the rates between victims and nonvictims declining by approximately .3 percent each month thereafter. By contrast, adolescent violent victimization is associated with a nearly 57 percent increase in the rate of marital first union formation at 17 years of age, but this effect declines more than twice as fast as that for cohabiting first unions (by .8 percent with each additional month). However, the effect of violent victimization did not differ significantly between the unadjusted models for the risk of cohabitation and marriage-although the difference in the rates of decline with time approaches statistical significance (not shown). Controlling for demographic characteristics, family en- 


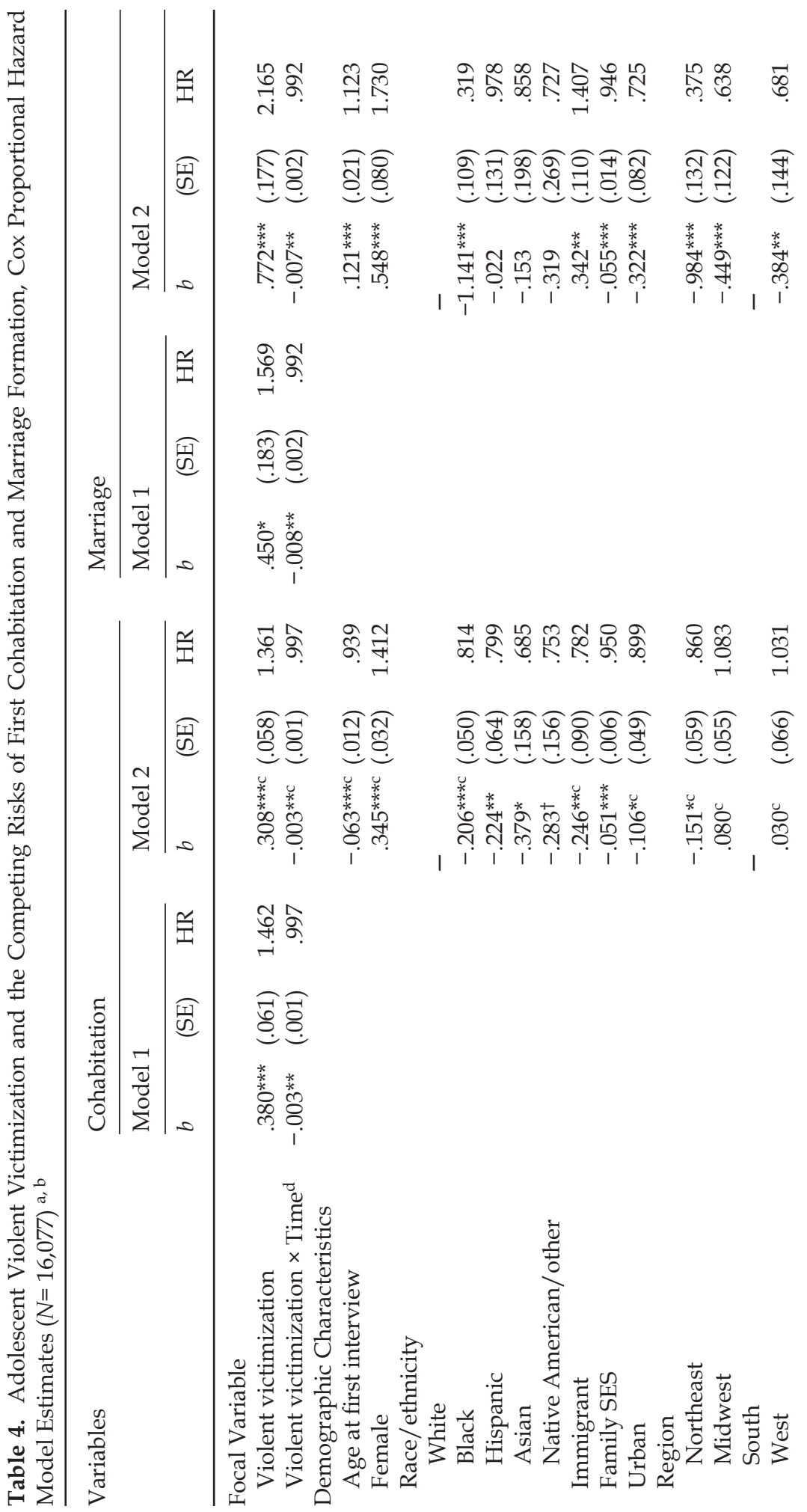




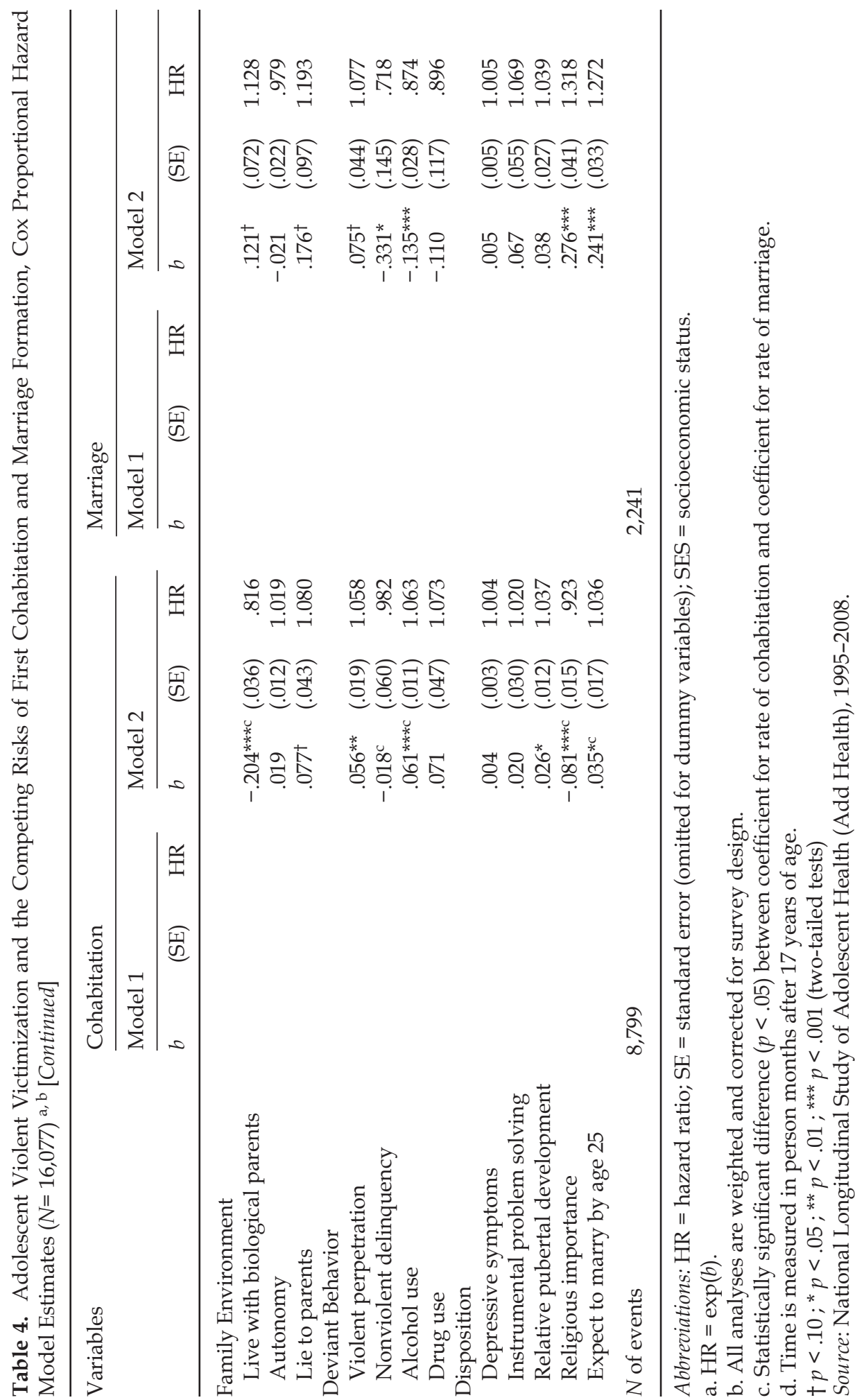


vironment, deviant behavior, and disposition, however, revealed that the effect of adolescent violent victimization on the rate of marriage formation is significantly larger than the effect on the rate of cohabitation.

Model 2 presents the adjusted effect of violent victimization. Net of controls, the effect of adolescent violent victimization on the rate of cohabitation was 36 percent higher for victims than for nonvictims at 17 years of age and declining at .3 percent each month thereafter. Entering the control measures in a stepwise fashion (models not shown) revealed that once we controlled for female and race/ethnicity, violent victimization was associated with a faster rate of union formation (approximately 66 percent higher at 17 years of age). This suppressor effect occurred because women are less apt to be victims of street violence but have higher rates of cohabitation than sameaged men, whereas non-Whites are more likely to have been victims but have lower rates of cohabitation than same-aged Whites. The other blocks of predictors each slightly reduced the effect of victimization, with the largest reduction occurring when we controlled for violent perpetration.

In contrast to the models for cohabitation, adjusting for all covariates substantially increased the effect of adolescent violent victimization on the rate of marital first union formation. Net of the controls, adolescent violent victimization more than doubles the rate of marital first union formation at 17 years of age, as victims have rates nearly 117 percent greater than those of nonvictims, and these rates decline by .7 percent each month after 17 years of age. Entering the controls in a stepwise manner indicated that several factors were suppressing this larger effect of violent victimization in the unadjusted models, including female, living with both biological parents, religious importance, and respondents' expectations of being married by 25 years of age -all of which are associated positively with the rate of marital first union formation but associated negatively with violent victimization. Race/ethnicity, urban residence, nonviolent delinquency, and alcohol use also suppressed the effect of violent victimization on the rate of marital first union formation, as Black respondents, those living in urban areas, those committing more nonviolent delinquent acts, and those with more frequent alcohol use were more likely to report violent victimization but have lower rates of marital first union formation.

Comparing the effect of select control variables between the models for cohabiting and marital first unions, the pattern of results largely conforms to prior literature. Women have higher rates of both types of union formation compared with men, whereas Black respondents have lower rates of both types of first union formation compared with Whites (and in both cases, the effect for marriage is larger). Immigrants are less likely to enter cohabiting unions and more likely to enter marital unions. Nonviolent delinquency is associated with lower, and violent perpetration is associated with higher, rates of both types of union formation (and the effects did not 
differ between the types). More frequent alcohol use increases the rate of cohabiting first union formation but decreases the rate of marital first union formation.

Even though violent victimization is associated with a substantially larger increase in the rate of marital, as opposed to cohabiting, first union formation, the practical impact is not as striking, given that most young adults' first unions are formed via cohabitation (Table 2; also see Kennedy and Bumpass, 2008). This fact also explains why the effect of violent victimization on the rate of any union formation is more similar to the rate of cohabiting, rather than of marital, first union formation. Nevertheless, overall, our findings suggest that experiencing violent victimization during adolescence is associated with precocious union formation, especially early marriage.

\section{Supplemental Analyses: Age Differences in the Experience of Violent Victimization}

Given the age heterogeneity of our sample, with our measure of adolescent violent victimization referring to experiences occurring within the past 12 months for youth 11 and 21 years of age, we conducted supplemental analyses to explore whether the developmental consequences of violent victimization differed by age. We direct readers to the online supporting information for the assumptions and details of these analyses, but note that these results suggest that violent victimization experienced by "younger" adolescents ( $\leq 16$ years of age) may have different effects on the rate of union formation than violent victimization experienced by "older" adolescents (>16 years of age). Violent victimization increases the rate of any first union formation similarly at 17 years of age for younger and older respondents - although the effect declines more steeply with time for younger respondents. However, it is only among younger respondents that the effects of violent victimization differ significantly among the types of first union. Among younger adolescents, violent victimization increases the rate of first cohabitation at 17 years of age by approximately 38 percent but increases the rate of first marriage at 17 years of age by an astounding 266 percent. Among older respondents, the effect of violent victimization is virtually identical for the rates of first cohabitation and first marriage formation - with victims of street violence approximately 59 percent more likely to form either type of union at 17 years of age. In fact, the rates of first cohabitation formation do not differ significantly between younger and older respondents. Thus, in line with both life course and criminological theories, which point to the salience of developmental timing, our supplemental analyses suggest that violent victimization in early adolescence may be associated with the formation of early marital unions especially, an effect that is pronounced but dissipates quickly. However, we urge caution in interpreting these results 
given the assumptions required to investigate developmental differences in the timing of violent victimization in Add Health.

\section{Summary and Discussion}

Guided by life course theory (Elder, Johnson, and Crosnoe, 2003) and prior research examining "early exits," the current study bridged scholarship in criminology and family sociology to examine the effect of adolescent violent street victimization on the timing of first union formation in young adulthood. Using longitudinal data from Add Health, our analyses were guided by two key research questions: 1) How is adolescent violent victimization related to the timing of first union formation in young adulthood, and 2) does adolescent violent victimization differentially affect the timing of cohabiting versus marital first union formation? We expected that adolescent victimization would increase the rate of first union formation but that the effect would decline with age, as cohabitation and marriage become more normative. Our results support this expectation, as we find that young adults who were victims of street violence in adolescence form unions substantially sooner than nonvictims. However, the effect of violent victimization on the rate of union formation wanes with age such that by the time they are past their mid-20s, victims have a reduced likelihood of first union formation.

Our competing risks analyses indicate that victimization has implications for the formation of both cohabiting and marital unions, but the effect on marital first union formation among victims is substantially larger than that for cohabitation at 17 years of age. However, this increased rate of marital first union formation among victims declines much more precipitously than the rate of cohabiting first union formation. Thus, it is especially early marriage that violent victimization jumpstarts, with more modest effects for early cohabitation formation - which is not surprising, given the increasing normalcy of cohabitation at younger ages. Our supplementary analyses also suggest that the increased rate of marital first union formation is especially pronounced for victims who were younger than 16 years of age at the first interview.

However, that the effect of violent victimization also is conditional on age in adulthood, with the effect of victimization intersecting with agegraded expectations for union formation, is especially noteworthy to life course criminology. Our findings illustrate a precocious exit from adolescence to adulthood, in support of prior research (Hagan and Foster, 2001; Haynie et al., 2009); yet the declining effect indicates that victimization has a more complex influence on union formation than simply producing an early exit as other scholars have shown with other risk outcomes. Although 
purely speculative, it may be that adolescent victims who did not enter a coresidential union by their early 20s are less able to do so later because their victimization experiences produced enough emotional baggage to render them undesirable mates for the dwindling pool of possible partners. Yet, as Table 2 indicates, similar proportions of adolescent victims of violence and nonvictims have ever formed a first coresidential union through their early 30s. This finding alone is interesting because prior research has pointed to the importance of spouses, and romantic partners in general, for producing desistance (Giordano, Schroeder, and Cernkovich, 2007; Sampson and Laub, 1990). Thus, because victims of street violence form coresidential unions earlier than nonvictims and are just as likely to have ever formed a union, there may be implications for future offending trajectories - to the extent that violent victimization and offending co-occur - via relationship stability and quality.

Indeed, crucial avenues for future research are to examine the stability and quality of the first coresidential unions formed by adolescent victims of street violence and the implications of this for long-term well-being. In terms of stability, we know that younger age at marriage is positively associated with divorce (Amato and Booth, 1997; Teachman, 2002) and that divorced persons have lower levels of psychological and economic well-being (Waite and Gallagher, 2000). Moreover, cohabiting unions formed at early ages are quite unstable, with high rates of dissolution (Schoen, Landale, and Daniels, 2007), and even if such cohabiting unions end because the couple marries, premarital cohabitation is itself a risk factor for divorce (Uecker and Stokes, 2008). The consequences of early unions may have even more detrimental lifecourse consequences for victims, as Sutherland (1947), in his theory of differential association, pointed to the importance of "priority," whereby relationships formed earlier in life have stronger influence than those formed later. Whether early marital and/or cohabiting union formation is similarly associated with instability among victims-including subsequent relationship formation and dissolution - is unknown. Evidence of relationship instability would suggest that these early unions are not beneficial for the long-term well-being of adolescent victims of violence, nor would we expect them to have beneficial consequences for desistance.

Desistance research also tells us that it is not necessarily the relationship itself that produces a reduction or cessation in offending but the quality of the relationship. One aspect of relationship quality that may be especially important to consider in future research is IPV. Prior research examining the link between IPV and "early exits" (Hagan and Foster, 2001; Haynie et al., 2009) has found that experiences with IPV in dating relationships are particularly consequential for producing the "end to adolescence"; yet it also could be that adolescent victimization in other realms (e.g., street violence, as exam- 
ined here) pushes victims into early unions characterized by IPV. That is, persons experiencing violent victimization may be at a higher risk of entering volatile intimate relationships (and of doing so at younger ages) such that an examination of the consequences of IPV may need to consider other victimization experiences that lead individuals into those relationships in the first place. This consideration is important given that early union formation is a risk factor for violence and aggression within those relationships (DeMaris et al., 2003). It also is important to consider cohabitation and marriage separately, given the higher prevalence of partner violence within cohabiting relationships (Brown and Bulanda, 2008; Kenney and McLanahan, 2006; Waite and Gallagher, 2000).

As we indicated previously, the implications of our findings for research on desistance depend on the degree to which violent victimization and offending co-occur. In fact, it is well established in criminology that victims of street violence and offenders often are the same individuals (Lauritsen, Sampson, and Laub, 1991; Menard, 2002). Despite this overlap, our findings show that adolescent violent victimization and deviant behavior have independent (and sometimes contradictory) effects on first union formation. For example, whereas adolescent violent victimization increases the risk of both marital and cohabiting first union formation, adolescent nonviolent delinquency and alcohol use are associated with a lower risk of first marriage but a higher risk (at least for alcohol use) of first cohabitation. Future research on desistance should be mindful of the fact that the impetus for first union formation among offenders - and the type of union formed - may depend on whether one also has experienced violent victimization, especially in early adulthood.

Overall, our findings are a step toward understanding the complicated link between adolescent violent victimization and adult coresidential union formation, making an effort to "broaden our understanding of how victimization shapes life fortunes" (Macmillan, 2001: 14). This investigation raises important additional questions for future scholarship in criminology. Despite this important first step in demonstrating the association between adolescent violent victimization and union formation, our findings are tempered by three key limitations. Of primary concern is that our measure of violent victimization only references experiences occurring within the 12 months preceding the wave I interview. We do not have information on the age when victimization first occurred or on the subsequent frequency of victimization experiences. Thus, even though current victims are likely to experience repeat victimization (Finkelhor, Turner, Ormrod, Hamby, et al., 2009; Lauritsen and Quinet, 1995), consequently, we have only a "snapshot" of victimization experiences. This limitation is key given life course theory's emphasis on the importance of developmental timing in lives. Our supplementary analyses endeavor to parse out this issue of timing, with violent 
victimization among younger respondents significantly increasing the risk of marital first union formation. However, given the required assumptions as detailed in the online supporting information, these results do not lead to clear conclusions.

A second limitation is that we cannot assess the mechanisms by which violent victimization increases the risk of early union formation. Prior research has suggested two likely explanations for the increased rate of first union formation among adolescent victims of street violence: lower status attainment (Macmillan, 2000; Macmillan and Hagan, 2004) and emotional need (Ruback and Thompson, 2001). Measurement limitations prevented us from adequately assessing the former possibility because we could not establish whether school enrollment or employment occurred before or after union formation. However, as described in the online supporting information, supplemental analyses including an indicator of whether one graduated high school or not did not diminish the estimated effect of violent victimization. Although high school completion is a limited measure of status attainment, the pattern of our results suggests that status attainment processes are not principally leading to higher rates of first union formation among victims. If victims are both less likely to be in school and less likely to be employed, as indicated in previous research, then we would expect violent victimization to be associated with lower rates of marital union formation given that steady employment is something both young men and women desire in potential marital partners (Thornton and Young-DeMarco, 2001). Yet we find that violent victimization is associated with a significantly higher rate of marriage in the late teens and early 20s. Of course, early union formation might subsequently contribute to the lower socioeconomic attainment of victims, and future research on the educational and employment trajectories of victims would be well served to consider this possibility.

Our pattern of findings thus suggests that the emotional impetus for union formation - that victims might seek out coresidential intimate relationships because of the longing for intimacy, social support, and to restore trust in others - may be especially important in propelling victims toward early union formation and disproportionately so toward early marriage. Unfortunately, Add Health lacks measures on the emotional constructs that would allow us to test these hypotheses. Future research, perhaps with data explicitly collected for these purposes, is needed to explore the extent to which victimization spurs adolescents to seek coresidential partners to fulfill these emotional or psychological needs, as well as the extent to which their early unions subsequently achieve that goal.

The final limitation is that, because Add Health is a school-based sample, our findings are limited to respondents who were listed on school rosters when the initial sample was drawn. As violent victimization is associated 
with high school dropout (Haynie et al., 2009; Macmillan and Hagan, 2004), the Add Health sample likely contains fewer victims of violence than in the total population, a difference that is apt to be more pronounced among older respondents where schooling is no longer compulsory. Given that education is positively associated with marriage and negatively associated with cohabitation (Thornton, Axinn, and Teachman, 1995; Waite and Gallagher, 2000), if such sample selection were operating, then we would expect our findings to be biased toward higher rates of marriage relative to cohabitation among older respondents who were victims of street violence (who, as a population, were more likely to complete high school given they were enrolled at 16 years of age). Yet, this is not what we find-as our supplemental analyses show that older victims have rates of first union formation that do not differ by marriage or cohabitation (see the online supporting information). This finding suggests that the school-based nature of the Add Health sample is not problematic for our study.

Notwithstanding these limitations, this research is among the first to address Macmillan's (2001: 14) call for scholars to examine the effect of victimization on the development and formation of intimate relationships. Our findings highlight the consequences of adolescent violent victimization for young adults' union formation-an outcome often neglected in life-course criminology. The consequences of such early coresidential union formation are as yet unclear; early union formation among victims of violence in adolescence may be a sign of resilience, or given the negative consequences associated with early unions identified in prior studies, it may be another indicator of cumulative disadvantage. Given the well-established link between victimization and offending, it is critical to examine union formation as an outcome in criminology because prior hardships in adolescence could potentially set the stage for the development of intimate relationships that do not lead to desistance or that at least have salient consequences for other offending trajectories in adulthood. Future research should extend the findings of the current study, exploring further the meaning, motivations, and consequences of coresidential union formation in such a vulnerable population.

\section{References}

Allison, Paul D. 1984. Event History Analysis: Regression for Longitudinal Event Data. Sage University Paper Series on Quantitative Applications in the Social Sciences, No. 07-046. Newbury Park, CA: Sage.

Amato, Paul R. 2000. The consequences of divorce for adults and children. Journal of Marriage and the Family 62:1269-87. 
Amato, Paul R., and Alan Booth. 1997. A Generation at Risk: Growing up in an Era of Family Upheaval. Cambridge, MA: Harvard University Press.

Amato, Paul R., Alan Booth, David R. Johnson, and Stacy J. Rogers. 2007. Alone Together: How Marriage in America Is Changing. Cambridge, MA: Harvard University Press.

Amato, Paul R., and Stacy J. Rogers. 1997. A longitudinal study of marital problems and subsequent divorce. Journal of Marriage and the Family 59:612-24.

Bearman, Peter S., and James Moody. 2004. Suicide and friendships among American adolescents. American Journal of Public Health 94:89-95.

Boivin, Michel, Shelley Hymel, and Ernest V. E. Hodges. 2001. Toward a process view of peer rejection and harassment. In Peer Harassment in School: The Plight of the Vulnerable and Victimized, eds. Janna Juvonen and Sandra Graham. New York: Guilford Press.

Booth, Alan, and John N. Edwards. 1985. Age at marriage and marital instability. Journal of Marriage and the Family 47:67-75.

Booth, Alan, Elisa Rustenbach, and Susan McHale. 2008. Early family transitions and depressive symptom changes from adolescence to early adulthood. Journal of Marriage and the Family 70:3-14.

Brown, Susan L., and Jennifer Roebuck Bulanda. 2008. Relationship violence in young adulthood: A comparison of daters, cohabitors, and marrieds. Social Science Research 37:73-87.

Brumbach, Barbara Hagenah, Aurelio Jose Figueredo, and Bruce J. Ellis. 2009. Effects of harsh and unpredictable environments in adolescence on development of life history strategies. Human Nature 20: 25-51.

Bumpass, Larry, and Hsien-Hen Lu. 2000. Trends in cohabitation and implications for children's family contexts in the United States. Population Studies 54:29-41.

Cherlin, Andrew J., Linda M. Burton, Tera R. Hurt, and Diane M. Purvin. 2004. The influence of physical and sexual abuse on marriage and cohabitation. American Sociological Review 69:768-89. 
Clarkberg, Marin, Ross M. Stolzenberg, and Linda J. Waite. 1995. Attitudes, values, and entrance into cohabitational versus marital unions. Social Forces 74:609-32.

Clausen, John S. 1991. Adolescent competence and the shaping of the life course. American Journal of Sociology 96:805-42.

Cleary, Sean D. 2000. Adolescent victimization and associated suicidal and violent behaviors. Adolescence 35:671-82.

Collins, W. Andrew. 2003. More than myth: The developmental significance of romantic relationships during adolescence. Journal of Research on Adolescence 13:1-24.

DeMaris, Alfred, Michael L. Benson, Greer L. Fox, Terrence Hill, and Judy Van Wyk. 2003. Distal and proximal factors in domestic violence: A test of an integrated model. Journal of Marriage and the Family 65: 652-67.

DeMaris, Alfred, and Catherine Kaukinen. 2005. Violent victimization and women's mental and physical health: Evidence from a national sample. Journal of Research in Crime and Delinquency 42:384-411.

Elder, Glen H., Jr., Monica Kirkpatrick Johnson, and Robert Crosnoe. 2003. The emergence and development of life course theory. In Handbook of the Life Course, eds. Jeylan T. Mortimer and Michael J. Shanahan. New York: Plenum Press.

Esbensen, Finn-Aage, David Huizinga, and Scott Menard. 1999. Family context and criminal victimization in adolescence. Youth \& Society 31:168-98.

Felson, Richard B., and Dana L. Haynie. 2002. Pubertal development, social factors, and delinquency among adolescent boys. Criminology 40:967-88.

Finkelhor, David, Heather Turner, Richard Ormrod, and Sherry L. Hamby. 2009. Violence, abuse, and crime exposure in a national sample of children and youth. Pediatrics 124:1411-23.

Finkelhor, David, Heather Turner, Richard Ormrod, Sherry Hamby, and Kristen Kracke. 2009. Children's exposure to violence: A comprehensive national survey. In Juvenile Justice Bulletin. Washington, DC: Office of Juvenile Justice and Delinquency Prevention, Office of Justice Programs, U.S. Department of Justice. 
Giordano, Peggy C., Ryan D. Schroeder, and Stephen A. Cernkovich. 2007. Emotions and crime over the life course: A neo-Meadian perspective on criminal continuity and change. American Journal of Sociology 112:1603-61.

Guerra, Nancy G., Kirk R. Williams, and Shelly Sadek. 2011. Understanding bullying and victimization during childhood and adolescence: A mixed methods study. Child Development 82:295-310.

Hagan, John. 1998. Life course capitalization and adolescent behavioral development. In New Perspectives on Adolescent Risk Behavior, ed. Richard Jessor. New York: Cambridge University Press.

Hagan, John, and Holly Foster. 2001. Youth violence and the end of adolescence. American Sociological Review 66:874-99.

Halpern, Carolyn Tucker, Selene G. Oslak, Mary L. Young, Sandra L. Martin, and Lawrence L. Kupper. 2001. Partner violence among adolescents in opposite-sex romantic relationships: Findings from the national longitudinal study of adolescent health. American Journal of Public Health 91:1679-85.

Halpern, Carolyn Tucker, Martha W. Waller, Aubrey Spriggs, and Denise Dion Hallfors. 2006. Adolescent predictors of emerging adult sexual patterns. Journal of Adolescent Health 39:926.e1-26.e10.

Harris, Kathleen Mullan, Carolyn T. Halpern, Eric A. Whitsel, Jon R. Hussey, Joyce Tabor, Pamela Entzel, and J. Richard Udry. 2009. The National Longitudinal Study of Adolescent Health: Research Design. http://www.cpc.unc. edu/projects/addhealth/design

Haynie, Dana L., Richard J. Petts, David Maimon, and Alex R. Piquero. 2009. Exposure to violence in adolescence and precocious role exits. Journal of Youth and Adolescence 38:269-86.

Haynie, Dana L., and Alex R. Piquero. 2006. Pubertal development and physical victimization in adolescence. Journal of Research in Crime and Delinquency 43:3-35.

Janoff-Bulman, Ronnie, and Irene H. Frieze. 1983. A theoretical perspective for understanding reactions to victimization. Social Issues 39:1-17.

Johnson, Monica Kirkpatrick, and Stefanie Mollborn. 2009. Growing up faster, feeling older: Hardship in childhood and adolescence. Social Psychology Quarterly 72:39-60. 
Kennedy, Sheela, and Larry Bumpass. 2008. Cohabitation and children's living arrangements: New estimates from the United States. Demographic Research 19:1663-92.

Kenney, Catherine T., and Sara S. McLanahan. 2006. Why are cohabiting relationships more violent than marriages? Demography 43:127-40.

Kiernan, Kathleen E. 1977. Age at puberty in relation to age at marriage and parenthood: A national longitudinal study. Annals of Human Biology 4:301-8.

King, Ryan D., and Scott J. South. 2011. Crime, race, and the transition to marriage. Journal of Family Issues 31:99-126.

Kobak, Roger, Natalie L. Rosenthal, Kristyn Zajac, and Stephanie D. Madsen. 2007. Adolescent attachment hierarchies and the search for an adult pairbond. New Directions for Child and Adolescent Development 2007:57-72.

Latzman, Robert D., and Raymond R. Swisher. 2005. The interactive relationship among adolescent violence, street violence, and depression. Journal of Community Psychology 33:355-71.

Lauritsen, Janet L. 2003. How Families and Communities Influence Youth Victimization. Washington, DC: Office of Juvenile Justice and Delinquency Prevention, Office of Justice Programs, U.S. Department of Justice.

Lauritsen, Janet L., and Kenna F. Davis Quinet. 1995. Repeat victimization among adolescents and young adults. Journal of Quantitative Criminology 11:143-66.

Lauritsen, Janet L., Robert J. Sampson, and John H. Laub. 1991. The link between offending and victimization among adolescents. Criminology 29:265-92.

Lonardo, Robert A., Wendy D. Manning, Peggy C. Giordano, and Monica A. Longmore. 2010. Offending, substance use, and cohabitation in young adulthood. Sociological Forum 25:787-803.

Macmillan, Ross. 2000. Adolescent victimization and income deficits in adulthood: Rethinking the costs of criminal violence from a life-course perspective. Criminology 38:553-88. 
Macmillan, Ross. 2001. Violence and the life course: The consequences of victimization for personal and social development. Annual Review of Sociology 27:1-22.

Macmillan, Ross, and John Hagan. 2004. Violence in the transition to adulthood: Adolescent victimization, education, and socioeconomic attainment in later life. Journal of Research on Adolescence 14:127-58.

Menard, Scott. 2002. Short- and long-term consequences of adolescent violent victimization. In Youth Violence Research Bulletin. Washington, DC: Office of Juvenile Justice and Delinquency Prevention \& Centers for Disease Control and Prevention.

Miles, Toni P., and Kathleen Malik. 1994. Menopause and African- American women: Clinical and research issues. Experimental Gerontology 29:511-8.

Osofsky, Joy D. 1995. The effects of exposure to violence on young children. American Psychologist 50:782-8.

Overbeek, Geertjan, Herma Zeevalkink, Ad Vermulst, and Ron H. J. Scholte. 2010. Peer victimization, self-esteem, and ego resilience types in adolescents: A prospective analysis of person-context interactions. Social Development 19:270-84.

Paternoster, Raymond, Robert Brame, Paul Mazerolle, and Alex R. Piquero. 1998. Using the correct statistical test for the equality of regression coefficients. Criminology 36:859-66.

Raley, R. Kelly, Sarah Crissey, and Chandra Muller. 2007. Of sex and romance: Late adolescent relationships and young adult union formation. Journal of Marriage and the Family 69:1210-26.

Ross, Catherine E., and John Mirowsky. 2009. Neighborhood disorder, subjective alienation, and distress. Journal of Health and Social Behavior 50:49-64.

Ruback, R. Barry, and Martie P. Thompson. 2001. Social and Psychological Consequences of Violent Victimization. Thousand Oaks, CA: Sage.

Ryan, Suzanne, Kerry Franzetta, Erin Schelar, and Jennifer Manlove. 2009. Family structure history: Links to relationship formation behaviors in young adulthood. Journal of Marriage and the Family 71:935-53. 
Sampson, Robert J., and John H. Laub. 1990. Crime and deviance over the life course: The salience of adult social bonds. American Sociological Review 55:609-27.

Sampson, Robert J., and John H. Laub. 1993. Crime in the Making: Pathways and Turning Points through Life. Cambridge, MA: Harvard University Press.

Scarpa, Angela. 2001. Community violence exposure in a young adult sample: Lifetime prevalence and socioemotional effects. Journal of Interpersonal Violence 16:36-53.

Schoen, Robert, Nancy S. Landale, and Kimberly Daniels. 2007. Family transitions in young adulthood. Demography 44:807-20.

Schreck, Christopher J., Melissa W. Burek, and Jason Clark-Miller. 2007. He sends rain upon the wicked: A study of religiosity's influence on violent victimization. Journal of Interpersonal Violence 22: 872-93.

Settersten, Richard A., Jr. 2003. Age structuring and the rhythm of the life course. In Handbook of the Life Course, eds. Jeylan T. Mortimer and Michael J. Shanahan. New York: Plenum Press.

Siegel, Rebecca S., Annette M. La Greca, and Hannah M. Harrison. 2009. Peer victimization and social anxiety in adolescents: Prospective and reciprocal relationships. Journal of Youth and Adolescence 38:1096-109.

Snyder, Howard N., and Melissa Sickmund. 2006. Juvenile Offenders and Victims: 2006 National Report. Washington, DC: Office of Juvenile Justice and Delinquency Prevention, Office of Justice Programs, U.S. Department of Justice.

Stanley, Scott M., Galena K. Rhoades, and Howard J. Markman. 2006. Sliding versus deciding: Inertia and the premarital cohabitation effect. Family Relations 55:499-509.

Sutherland, Edwin H. 1947. Principles of Criminology, 4th ed. Philadelphia, PA: Lippincott.

Teachman, Jay D. 2002. Stability across cohorts in divorce risk factors. Demography 39:331-51.

Teachman, Jay D. 2003. Childhood living arrangements and the formation of coresidential unions. Journal of Marriage and the Family 65: 507-24. 
Thornberry, Terence P. 1987. Toward an interactional theory of delinquency. Criminology 25:863-92.

Thornton, Arland, William G. Axinn, and Daniel H. Hill. 1992. Reciprocal effects of religiosity, cohabitation, and marriage. American Journal of Sociology 98:628-51.

Thornton, Arland, William G. Axinn, and Jay D. Teachman. 1995. The influence of school enrollment and accumulation on cohabitation and marriage in early adulthood. American Sociological Review 60: 762-74.

Thornton, Arland, and Linda Young-DeMarco. 2001. Four decades of trends in attitudes toward family issues in the United States: The 1960s through the 1990s. Journal of Marriage and the Family 63:1009-37.

Turner, Heather A., David Finkelhor, and Richard Ormrod. 2006. The effect of lifetime victimization on the mental health of children and adolescents. Social Science and Medicine 62:13-27.

Uecker, Jeremy E., and Charles E. Stokes. 2008. Early marriage in the United States. Journal of Marriage and the Family 70:835-46.

Uggen, Christopher. 2000. Work as a turning point in the life course of criminals: A duration model of age, employment, and recidivism. American Sociological Review 65:529-46.

Waite, Linda J., and Maggie Gallagher. 2000. The Case for Marriage: Why Married People Are Happier, Healthier, and Better Off Financially. New York: Doubleday.

Whitaker, Daniel J., Tadesse Haileyesus, Monica Swahn, and Linda S. Saltzman. 2007. Differences in frequency of violence and reported injury between relationships with reciprocal and nonreciprocal intimate partner violence. American Journal of Public Health 97:941-7.

Wickrama, Thulitha, K. A. S. Wickrama, and Diana L. Baltimore. 2010. Adolescent precocious development and young adult health outcomes. Advances in Life Course Research 15:121-31.

Wolfinger, Nicholas H. 2003. Parental divorce and offspring marriage: Early or late? Social Forces 82:337-53. 


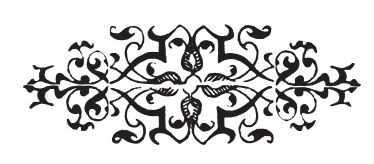

Danielle C. Kuhl is an assistant professor in the Department of Sociology at Bowling Green State University, where she also is an affiliate with the Center for Family and Demographic Research. Her research interests include neighborhood effects on crime, delinquency, and substance use, and the implications of adolescent risk behaviors and risk exposure for adult outcomes. Prior publications have appeared in Criminology, Journal of Quantitative Criminology, American Sociological Review, and American Journal of Sociology.

David F. Warner is an assistant professor in the Department of Sociology at the University of Nebraska - Lincoln. A life course sociologist and demographer, his research emphasizes marriage and family relationships as mechanisms by which inequalities, particularly by gender and race/ethnicity, unfold and are reinforced. His work has appeared in Journal of Health and Social Behavior, Social Science Research, Social Science and Medicine, and Population Research and Policy Review.

Andrew Wilczak is an assistant professor in the Department of Sociology at Wilkes University. His research interests include the effect of victimization on adolescent and adult offending, mental health, and the role of neighborhood and family characteristics in the desistance process.

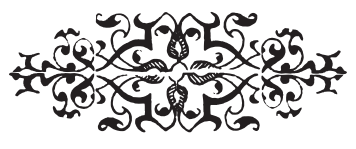




\section{SUPPORTING INFORMATION FOR}

“ADOLESCENT VIOLENT VICTIMIZATION AND PRECOCIOUS UNION FORMATION"*

DANIELLE C. KUHL

DAVID F. WARNER

ANDREW WILCZAK

* Published in Criminology, volume 50, issue 4, 2012. 


\section{ADDITIONAL VARIABLES CONSIDERED IN SUPPLEMENTAL ANALYSES}

As noted in our discussion of our focal independent variable of street victimization, our final results were robust to controls for physical and sexual abuse by a parent or adult. In waves III and IV of Add Health, respondents were asked - in slightly different ways - to report retrospectively on mistreatment by "parents or other adults who took care of" them. To create equivalencies between

the waves, we constructed indicators of physical abuse and sexual abuse reported by respondents to have first occurred before 11 years of age. We then created dummy variables for "ever" reporting each measure. In supplemental analyses, which were necessarily limited to respondents interviewed in waves III or IV, we included these dummy variables. The results indicated that although both physical and sexual abuse were associated with earlier formation of cohabiting (but not of marital) first unions, the effect of adolescent violent victimization was nearly identical to the effect when these familial violence measures were excluded. As the effect of violent victimization was robust to these controls for familial violence, we excluded these variables from the final model as their inclusion unnecessarily limits the risk set and results in a 14 percent case loss $(n=2,082)$.

In preliminary analyses, we also tested the effects of several other control variables. One important consideration was educational attainment, which is linked to adolescent violent victimization (Macmillan, 2000; Macmillan and Hagan, 2004) as well as to cohabiting and marital union formation (Thornton, Axinn, and Teachman, 1995; Waite and Gallagher, 2000). Add Health did not 
collect detailed schooling histories from respondents; thus, lacking information on the start and stop dates of education, we cannot ascertain whether school enrollment occurred before or after union formation. However, in supplemental models limited to respondents interviewed at wave III or wave IV, the inclusion of a dummy variable for whether one dropped out of high school (admittedly a crude indicator of diminished status attainment) did not reduce the estimated effect of violent victimization - suggesting that the differences in union timing that we document are not the product of the lower educational attainment of victims.

We also considered several measures of parent-adolescent relations, such as the extent to which respondents felt "close to" their parents and their parents "care[d] about" them, and a direct measure of parental monitoring (from the parent interview), but these measures were not significantly associated with union timing and we thus excluded them from our final models. We considered a measure of problem drinking, also, but again this was not significant and we excluded it from final models.

We tested for the effects of two additional dispositional measures-low intelligence and having a temper-but ultimately excluded these from our models as well. Intelligence (as measured by an abbreviated version of the Peabody Picture Vocabulary Test-Revised) was not associated with the risk of either marriage or cohabitation (and thus cannot mediate the effect of violent victimization), and its inclusion would have resulted in approximately 5 percent case loss. A measure of temper (whether the respondent had a "bad temper," as 
assessed by the respondent's parent) was significantly associated with entering a cohabiting first union, as opposed to marrying or remaining single, but only for males. However, the addition of temper was not associated with any practical reduction in the effect of adolescent violent victimization when other variables were included in the model. Given this, and the fact that its inclusion would have substantially reduced the cases available for analysis, as almost 15 percent of respondents did not have a valid parent interview, we opted to omit it. Finally, we considered an additional measure of future orientation - the expectation that one will attend college — but we excluded this from our final models because it was not associated with union formation when other covariates were included in the model.

\section{AGE DIFFERENCES IN THE EXPERIENCE OF VIOLENT VICTIMIZATION}

Our main analyses examined the effect of adolescent violent victimization on risk of first union formation, differentiating between marital and cohabiting unions, beginning at 17 years of age. As described in the text, reports of adolescent violent victimization referred to experiences in the year prior to respondent's first interview. Given the nature of the Add Health sample, this means that our measure captures experiences occurring to individuals who were anywhere between 11 and 21 years of age. The developmental complexity of adolescence leads to the expectation that violent victimization at 13 years of age has different consequences than victimization at 18 years of age. Unfortunately, we cannot examine such timing issues directly with the age-heterogeneous Add Health data because we cannot assess when victimization first occurred. 
Nevertheless, comparing the effect of violent victimization on our outcomes for younger and older respondents provided some evidence of such timing effects under a certain number of conditions. First, drawing on life-course theory, we expect that violent victimization first experienced in early adolescence would be of greater consequence than victimization experienced in late adolescence. Second, given that the incidence of violent victimization increases with age through adolescence and the absence of information about when one was first victimized, comparing a younger group of adolescent victims with an older group of adolescent victims means that we are likely comparing a homogenous group of early adolescent victims (younger respondents) with a heterogeneous group of late adolescent victims (older respondents). This latter group is heterogeneous because it contains both those first victimized in later adolescence as well as those first victimized in early adolescence (repeat victims), and because the consequences of victimization may differ for these two groups, this likely results in the estimated effect of victimization to be weaker when the groups are pooled as required here. By contrast, we might expect the effect of violent victimization to be greater for younger victims, as prior victimization predicts future victimization and such accumulation of adversity should produce stronger effects. Furthermore, because age and cohort are synonymous in Add Health, we must assume that there are no cohort differences in the effect of violent victimization (and we know of no prior research to suggest such effects in the Add Health birth cohorts). Under these circumstances, then, any differences between younger and older victims may indicate that the timing of victimization 
matters. Such conclusions would necessarily be tentative, of course.

Accordingly, we tested the proposition that earlier victimization may matter more for first union formation by stratifying the sample at 16 years of age and re-estimating our models. As with the main results, we first estimated models examining the rate of any first union formation and then estimated models for the rates of cohabiting and marital first union formation under competing risks. We used equality of coefficient tests (Paternoster et al. 1998) to compare the effect of violent victimization across models and by age group. We present the estimated effect of violent victimization and comparisons between models in table S.1. As described in the text, these results indicate that—although violent victimization increases the rate of any first union formation similarly at 17 years of age for younger and older respondents—only among younger respondents does the effect of violent victimization significantly differ among the types of first union; among older respondents, the effect of violent victimization is virtually identical for the rates of first cohabitation and first marriage formation. In fact, the rates of first cohabitation formation do not significantly differ between younger and older respondents. We did not detect any statistically significant gender differences in these age effects (not shown). 
Table S.1. Age Differences in the Experience of Adolescent Violent Victimization and the Risk of First Union Formation, Cox Proportional Hazard Model Estimates $(N=16,077)^{\mathrm{a}, \mathrm{b}, \mathrm{c}}$

\begin{tabular}{|c|c|c|c|c|c|c|c|c|c|}
\hline \multirow[t]{3}{*}{ Panels } & & & & \multicolumn{6}{|c|}{ Competing Risks } \\
\hline & \multicolumn{3}{|c|}{ Any First Union } & \multicolumn{3}{|c|}{ Cohabitation } & \multicolumn{3}{|c|}{ Marriage } \\
\hline & $b$ & (SE) & HR & $b$ & (SE) & HR & $b$ & (SE) & HR \\
\hline \multicolumn{10}{|l|}{ Panel A: Younger Respondents ${ }^{\mathrm{d}}$} \\
\hline Violent victimization & $.480 * * *$ & $(.117)$ & 1.616 & $.324 * * *^{\mathrm{f}}$ & $(.088)$ & 1.382 & $1.297 * * * \varepsilon$ & $(.288)$ & 3.657 \\
\hline Violent victimization $\times$ Time $^{\mathrm{e}}$ & $-.007 * * * \mathrm{~g}$ & $(.002)$ & .993 & $-.006 * * *$ & $(.002)$ & .994 & $-.015^{* * \mathrm{~g}}$ & $(.005)$ & .985 \\
\hline$N$ of events & & 4,687 & & & 3,860 & & & 827 & \\
\hline \multicolumn{10}{|l|}{ Panel B: Older Respondents ${ }^{\mathrm{d}}$} \\
\hline Violent victimization & $.366^{* * *}$ & $(.086)$ & 1.463 & $.344 * * *$ & $(.094)$ & 1.411 & $.341^{\dagger}$ & $(.203)$ & 1.407 \\
\hline Violent victimization $\times$ Time $^{\mathrm{e}}$ & $-.003^{*}$ & $(.001)$ & .997 & $-.003^{\dagger}$ & $(.001)$ & .997 & -.003 & $(.002)$ & .997 \\
\hline$N$ of events & & 6,353 & & & 4,939 & & & 1,414 & \\
\hline
\end{tabular}

ABBREVIATIONS: $\mathrm{HR}$ = hazard ratio; $\mathrm{SE}=$ standard error (omitted for dummy variables).

${ }^{\mathrm{a}} \mathrm{HR}=\exp (b)$.

${ }^{\mathrm{b}}$ All analyses are weighted and corrected for survey design.

${ }^{c}$ Controls for demographic characteristics, family environment, deviant behavior, and disposition are included in all models but omitted from table.

${ }^{\mathrm{d}}$ Younger respondents are those who were less than 16 years of age at the first interview, whereas older respondents are those who were

16 years of age or older at the first interview.

e Time is measured in person months after 17 years of age.

${ }^{\mathrm{r}}$ Statistically significant difference $(p<.05)$ between coefficient for rate of cohabitation and coefficient for rate of marriage

${ }^{\mathrm{g}}$ Statistically significant difference $(p<.05)$ between coefficient for younger respondents and older respondents.

${ }^{\dagger} p<.10 ; * p<.05 ; * * p<.01 ; * * * p<.001$ (two-tailed tests).

Source: National Longitudinal Study of Adolescent Health (Add Health), 1995-2008. 


\section{REFERENCES}

Macmillan, Ross. 2000. Adolescent victimization and income deficits in adulthood: Rethinking the costs of criminal violence from a life-course perspective. Criminology 38:553-88.

Macmillan, Ross, and John Hagan. 2004. Violence in the transition to adulthood: Adolescent victimization, education, and socioeconomic attainment in later life. Journal of Research on Adolescence 14:127-58.

Paternoster, Raymond, Robert Brame, Paul Mazerolle, and Alex R. Piquero. 1998. Using the correct statistical test for the equality of regression coefficients. Criminology 36:859-66.

Thornton, Arland, William G. Axinn, and Jay D. Teachman. 1995. The influence of school enrollment and accumulation on cohabitation and marriage in early adulthood. American Sociological Review 60:762-74.

Waite, Linda J., and Maggie Gallagher. 2000. The Case for Marriage: Why Married People Are Happier, Healthier, and Better Off Financially. New York: Doubleday. 